\title{
Vibration measurement of rotating blades using a root embedded PZT sensor
}

\author{
M. Sunar ${ }^{\mathrm{a}}$ and B.O. Al-Bedoor ${ }^{\mathrm{b}}$ \\ ${ }^{a}$ Mechanical Engineering Department, King Fahd University of Petroleum \& Minerals, Dhahran 31261, Saudi \\ Arabia \\ E-mail: mehmets@kfupm.edu.sa \\ ${ }^{\mathrm{b}}$ Mechanical Engineering Department, University of Jordan, P. O. Box 13568, Amman 11942, Jordan \\ E-mail: albedoor@ju.edu.jo
}

Received 28 November 2005

Revised 15 March 2007

\begin{abstract}
Finite element and experimental studies are carried out to test the suitability of a piezoelectric (PZT) sensor in measuring vibrations of blades modeled as beams. The rotating system contains twelve blades mounted to the shaft through a rotor. The PZT sensor is secured in the root between the rotor and blade. First, finite element results are obtained using the finite element package ANSYS. A modal analysis is performed on the system to identify modes and mode shapes. Transient, harmonic and steady-state responses are then computed to test the ability of the PZT sensor in generating signals for blade vibrations. For the experimental part, the blade vibration signals are produced using the PZT sensor and a strain-gage, and the outputs are compared with each other. From both the finite element and experimental results, it is concluded that the root-embedded PZT sensor can be effectively used for blade vibration measurements in a wide range of cases.
\end{abstract}

\section{Introduction}

The problem of blade vibrations has been recognised as one major and costly cause of turbomachinery failures. Due to the researcher and the designer knowledge of the complexities in blade vibration measurements, theoretical and numerical studies have been proposed to make sure that the designed blade will work safely within the machine speed range.

Comprehensive and numerical models addressing blade vibrations and stresses were published in the last two decades due to much progress in computers and microprocessors. In the literature survey by Srinivasan [1], the disk-blade vibrations were categorized into structural and aero-elastic type vibrations. The Finite Element Method (FEM) was used as a numerical technique for the modal and vibration analysis of blades by Bachau and Hong [2], and Jianzhong et al. [3]. The FEM was applied to model a helicopter rotor blade by Roy and Ganguli [4] for qualitatively investigating the effect of damage growth on the modal frequencies. In another finite element study, a turbine blade was modeled by Yardimoglu and Inman [5] including the centrifugal force field and root flexibility effects to compute natural frequencies. Some other studies were devoted to the interaction between the blade vibrations and rotor dynamics [6,7]. The problem of shaft torsional vibrations coupled with the blade vibrations was addressed by Okabe et al. [8], where a lumped parameter model for blade and shaft torsional vibrations was developed. The system was divided into blade and shaft subsystems for which a simple mass-spring system method was adopted. The two subsystems were then re-coupled and simulated. Based on the general multibody dynamics approach, a coupled dynamic model for blade-bending and shaft-torsional vibrations was studied by Al-Bedoor [9]. In this model, no separation between the blade and shaft modeling was needed as they were considered from the basic geometrical approach. The model has proved that the coupled dynamics of both shaft torsional and blade vibrations should be considered when addressing either one of these vibration mechanisms in rotating machinery. 
Despite difficulties in measuring vibrations of rotating blades, many researchers and manufacturers have invested their efforts in developing techniques for blade vibration measurements due to the importance of the problem. A study for the analysis and solution of a non-synchronous vibration problem in the last row turbine blade of a large industrial combustion turbine was reported by Scalzo et al. [10]. Blade vibrations signals were transmitted from strain gages using a telemetry system. Slip rings were not used, because they are known to produce much noise into the signal. Strain gages were also used by Tang and Dowell [11] for blade vibration measurements in their experimental set-up. Experimental results on the vibration measurements of rotating blades via a telemetry system were reported by Fan et al. [9]. A theoretical and experimental study on blade stresses under constant speed and transient conditions with non-linear damping was carried out by Rao and Vyas [12]. Tri-axial set strain gages near the blade root were used and the signal was processed through a slip-ring mechanism. Optimal placement of strain gages for rotating blade vibrations was studied by Szwedowicz et al. [13]. The optimum gage positions were based on sensitivity, orthogonality gradient and distance criteria. To this end one recognizes the wide use of strain gages in measuring blade vibrations. Some problems associated with the use of strain gages for the blade vibration measurements can be identified as: (1) where to locate the strain gages rosettes when dealing with an actual blade of complex shape, (2) how to transmit the signal to be further processed and analyzed, and (4) how long strain gages rosettes are going to survive.

Laser-doppler and optical measuring methods are also utilized in vibration measurement systems. A fibre-optic laser-doppler probe was proposed by Cookson and Bandyopadhyay [14] for the vibration analysis of rotating machines. The main limitation of this study is that the technique depends on frequency shifting that limits the rotating speed. Vibration measurement of a naval propeller rotating in water using a tracking laser vibrometer was performed by Castellini and Santolini [15], where the following troubles were encountered: Firstly, the experiments were confined to a low speed of about 600 revolutions per minute. Then, the laser "speckle" was producing noise that was greater than the vibration signal itself. Moreover, the problems of changing of the refraction-index, forming of water bubbles and absorption of light were observed. Finally, the problem of misalignment between the rotational axis and the laser vibrometer was also noticed. Despite these problems it was reported that the bending is the dominant vibration mode in rotating blades.

The approach of indirect measurements has been known for a long time [16]. Accelerometers at the casing of a compressor near the blade tips were attached by Mathioudakis et al. [17] to measure the blade vibrations. The collected vibration signals are rich in frequency contents. This method has shown a great deal of uncertainties when blade vibrations are to be monitored, as a result of the contribution of almost all working fluid and machine types of instabilities in addition to the acoustical and housing/foundation problems.

These investigations with the theoretical work of Al-Bedoor [18] indicate that the blade vibration monitoring via torsional vibration measurements is a promising technique. However, torsional vibration measurement techniques are many and are still in the development stage from both the aspects of pick-ups and data processing tools. Hence, the need of finding a more direct technique for blade vibration measurements is much in demand and the utilization of new materials for sensors like piezoelectric materials for this purpose is very attractive. The piezoelectric materials have been used as sensors for a long time in vastly different areas and the corresponding technologies have been well-developed. The survey paper by Sunar and Rao [19] reports on the phenomenon of piezoelectricity and various applications of piezoelectric materials. Some of the advantages of these materials can be listed as durability, sensitivity, precision and high frequency bandwidth, which are important for the blade vibration measurements. Therefore, motivated by the favourable characteristics of piezoelectric materials, this study aims at investigating the suitability of a piezoeceramic (PZT) material in sensing and measuring the blade vibrations of a rotating system. The material (sensor) is placed at the root of one of twelve blades of the system. The numerical part reports on the finite element modeling and analysis aspects using the ANSYS software [20]. The measurements are made using the PZT material, a strain-gage system, a casing accelerometer and a vertical proximity probe, but the results are reported only for the PZT material and the strain gage system due to space limitations.

\section{Finite element part}

\subsection{Modal analysis}

Due to the geometrical complexity of the rotating system, the ANSYS software is used for the finite element modeling and analysis. The three-dimensional model of the rotating system is shown in Fig. 1 and a zoomed view 
Table 1

Material properties

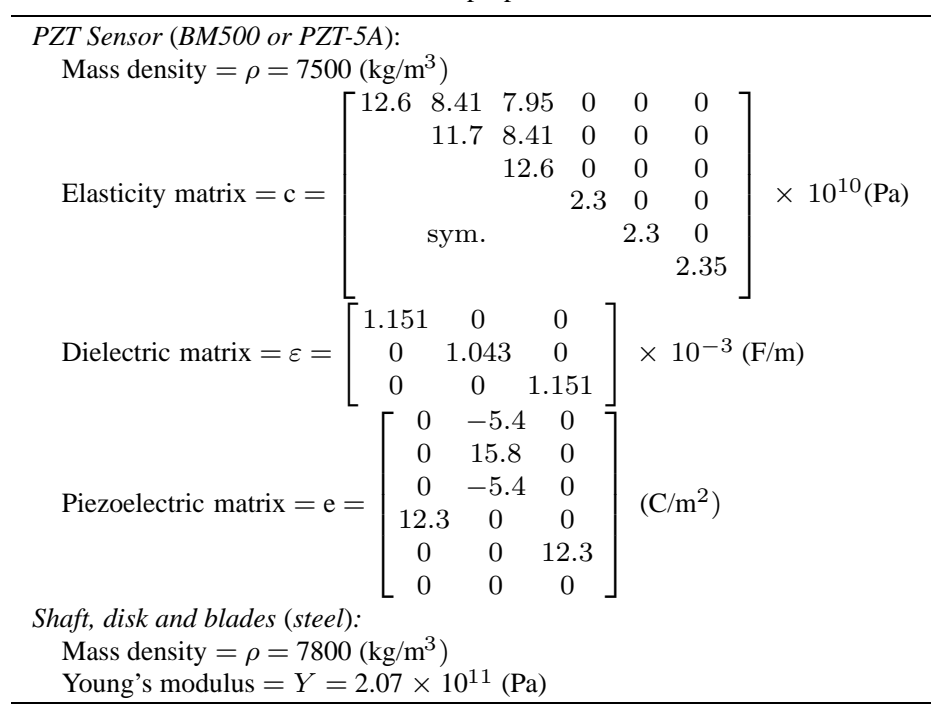

Table 2

Dimensions
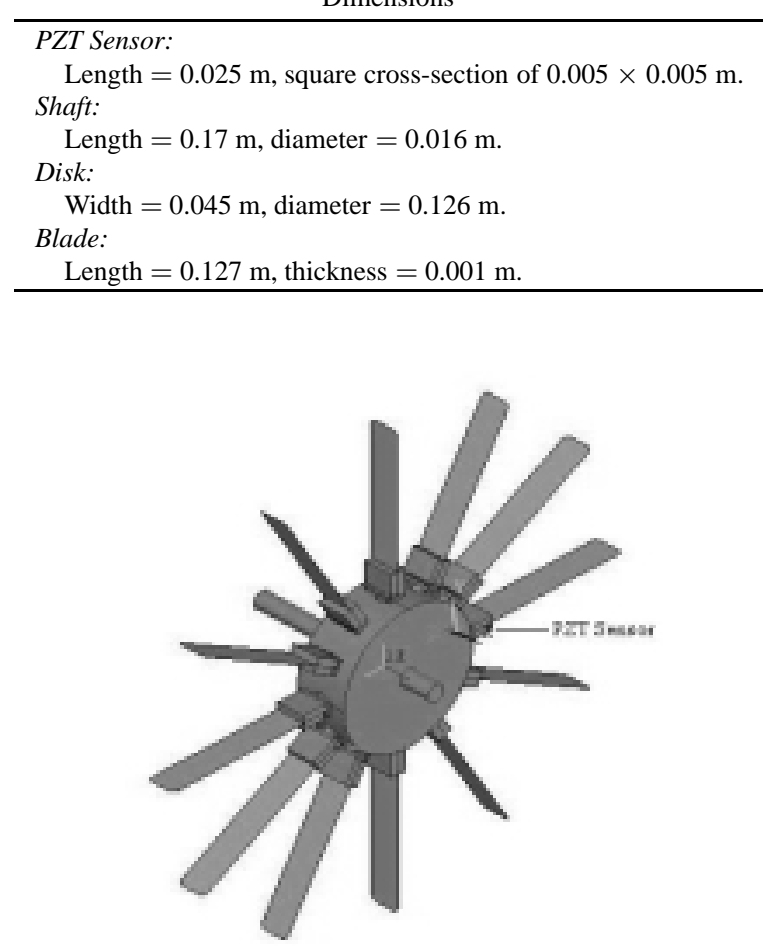

Fig. 1. Rotating system.

around the PZT sensor is provided in Fig. 2. As seen in Fig. 1, the shaft and disk are modeled as volumes meshed with three-dimensional solid elements and the blades are modeled as areas meshed with shell elements. The PZT sensor is meshed with three-dimensional solid elements and a perfect contact is assumed between the sensor, blade and disk. The finite element mesh of the whole system has resulted in 18,407 finite elements in total. The piezoelectric 


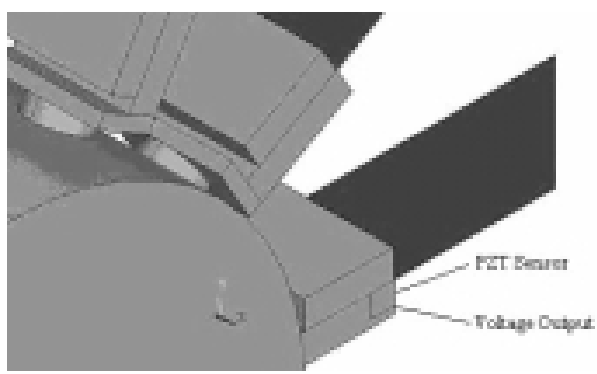

Fig. 2. PZT sensor zoomed.

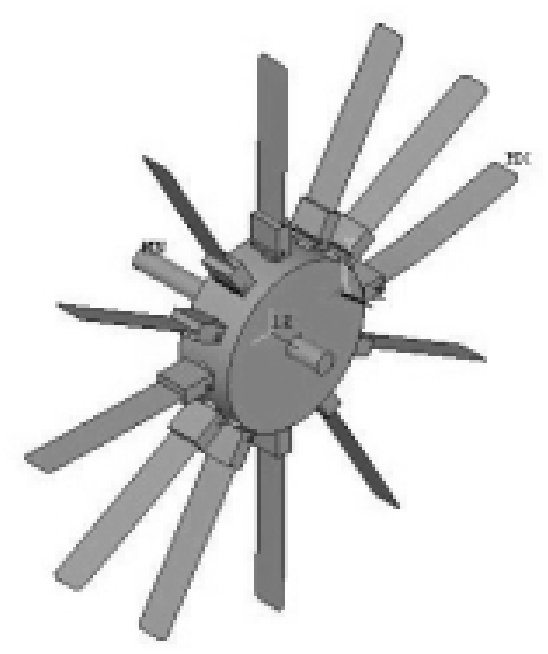

Fig. 3. Mode shape at $51.778 \mathrm{~Hz}$ of natural frequency (no rotation).

material is the BM500 piezoelectric material block provided by the Sensor Technology of Canada. The material properties of the PZT material, shaft, disk and blades are listed in Table 1 and their dimensions are given in Table 2.

The developed three-dimensional model is solved for modes (natural frequencies) and mode shapes for the nonrotating and rotating conditions. The effect of rotation in ANSYS is imposed using the stress stiffening and spin softening effects [20]. The natural frequencies of such three-dimensional model are many and only the lowest 40 natural frequencies are given in Table 3, for the non-rotating system and for the system rotating at speeds of 20 and $40 \mathrm{~Hz}$.

The first natural frequency of Table $3(28.190 \mathrm{~Hz})$ is the torsional natural frequency, which represents rigid rotation of the disk-blade assembly about the axis of the shaft. The next 12 frequencies represent the first bending mode of the 12 blades. It is observed that the first one is $51.778 \mathrm{~Hz}$ while the rest eleven frequencies are about $52.8 \mathrm{~Hz}$. This behavior can be explained based on the existence of the PZT material underneath one of the blades that has softened it and has lowered its corresponding natural frequency. The corresponding mode shape is shown in Fig. 3. The modes with natural frequencies numbering 13 and 14 in Table $3(181.53 \mathrm{~Hz}$ and $259.9 \mathrm{~Hz})$ have developed due to interactions between the blade and shaft vibration modes. The frequencies numbering 15 to 27 in Table 3 in the range from $323.62 \mathrm{~Hz}$ to $343.83 \mathrm{~Hz}$ can be attributed to the $2^{\text {nd }}$ bending modes of the blades, one of which can be seen in Fig. 4. These modes are softened by the shaft torsional flexibility, and the mistuning can also be observed due to the presence of the PZT material under one of the blades. The remaining frequencies in Table 3 (28-39) correspond to the torsional vibration modes of the blades about their axis. 
Table 3

Natural frequencies of the system in $\mathrm{Hz}$

\begin{tabular}{|c|c|c|c|}
\hline No & $f=0 \mathrm{~Hz}$ & $f=20 \mathrm{~Hz}$ & $f=40 \mathrm{~Hz}$ \\
\hline 1 & 28.190 & 34.823 & 49.314 \\
\hline 2 & 51.778 & 56.662 & 69.098 \\
\hline 3 & 52.799 & 57.690 & 70.174 \\
\hline 4 & 52.811 & 57.701 & 70.184 \\
\hline 5 & 52.816 & 57.703 & 70.194 \\
\hline 6 & 52.829 & 57.720 & 70.205 \\
\hline 7 & 52.836 & 57.729 & 70.212 \\
\hline 8 & 52.845 & 57.734 & 70.221 \\
\hline 9 & 52.849 & 57.741 & 70.231 \\
\hline 10 & 52.856 & 57.746 & 70.236 \\
\hline 11 & 52.858 & 57.755 & 70.252 \\
\hline 12 & 52.863 & 57.759 & 70.256 \\
\hline 13 & 181.53 & 182.57 & 185.29 \\
\hline 14 & 259.90 & 268.93 & 294.54 \\
\hline 15 & 323.62 & 333.74 & 354.01 \\
\hline 16 & 324.32 & 340.88 & 359.83 \\
\hline 17 & 329.23 & 341.06 & 360.49 \\
\hline 18 & 334.91 & 341.97 & 362.32 \\
\hline 19 & 334.95 & 342.01 & 362.35 \\
\hline 20 & 335.00 & 342.07 & 362.44 \\
\hline 21 & 335.02 & 342.09 & 362.45 \\
\hline 22 & 335.07 & 342.14 & 362.53 \\
\hline 23 & 335.50 & 342.67 & 362.91 \\
\hline 24 & 335.98 & 343.14 & 363.34 \\
\hline 25 & 336.31 & 343.34 & 363.56 \\
\hline 26 & 343.20 & 382.96 & 384.74 \\
\hline 27 & 343.83 & 385.27 & 386.79 \\
\hline 28 & 532.92 & 533.34 & 534.34 \\
\hline 29 & 533.24 & 533.63 & 534.63 \\
\hline 30 & 533.30 & 533.63 & 534.67 \\
\hline 31 & 534.71 & 535.08 & 536.05 \\
\hline 32 & 536.46 & 536.95 & 538.11 \\
\hline 33 & 536.80 & 537.27 & 538.45 \\
\hline 34 & 536.99 & 537.43 & 538.57 \\
\hline 35 & 537.07 & 537.47 & 538.63 \\
\hline 36 & 537.09 & 537.48 & 538.65 \\
\hline 37 & 537.71 & 538.14 & 539.31 \\
\hline 38 & 537.96 & 538.39 & 539.57 \\
\hline 39 & 538.05 & 538.46 & 539.64 \\
\hline
\end{tabular}

\subsection{Transient response}

To investigate the response of the embedded PZT material to different dynamic loadings of blades the model is simulated for:

1. Step input at the tip of the blade with the embedded PZT sensor.

2. Step loading at the tip of the blade opposite to the one with the embedded PZT sensor.

3. Rubbing of blade tips while rotating.

4. Broad band white noise force at the blade tip.

The resulting PZT sensor voltage responses are presented in time and frequency domains.

\subsubsection{Step input}

The blade under which the PZT material is embedded is acted upon by a step force of magnitude of $1.735 \mathrm{~N}$ in the + Y direction (Fig. 1) and the resulting PZT voltage outputs are monitored. The voltage signal produced by the PZT sensor for the non-rotating system and its frequency spectrum are shown in Figs 5 and 6. The PZT voltage signal frequency spectrum shows the highest amplitude at around $52 \mathrm{~Hz}$ and a frequency component at $260 \mathrm{~Hz}$ with very small amplitude. 


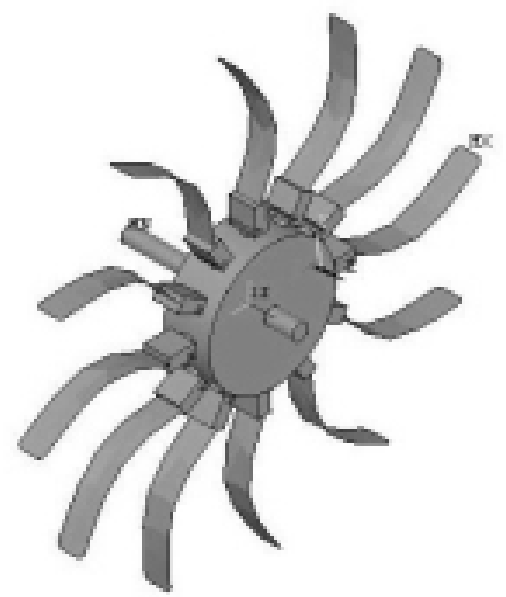

Fig. 4. Mode shape at $259.9 \mathrm{~Hz}$ of natural frequency (no rotation).

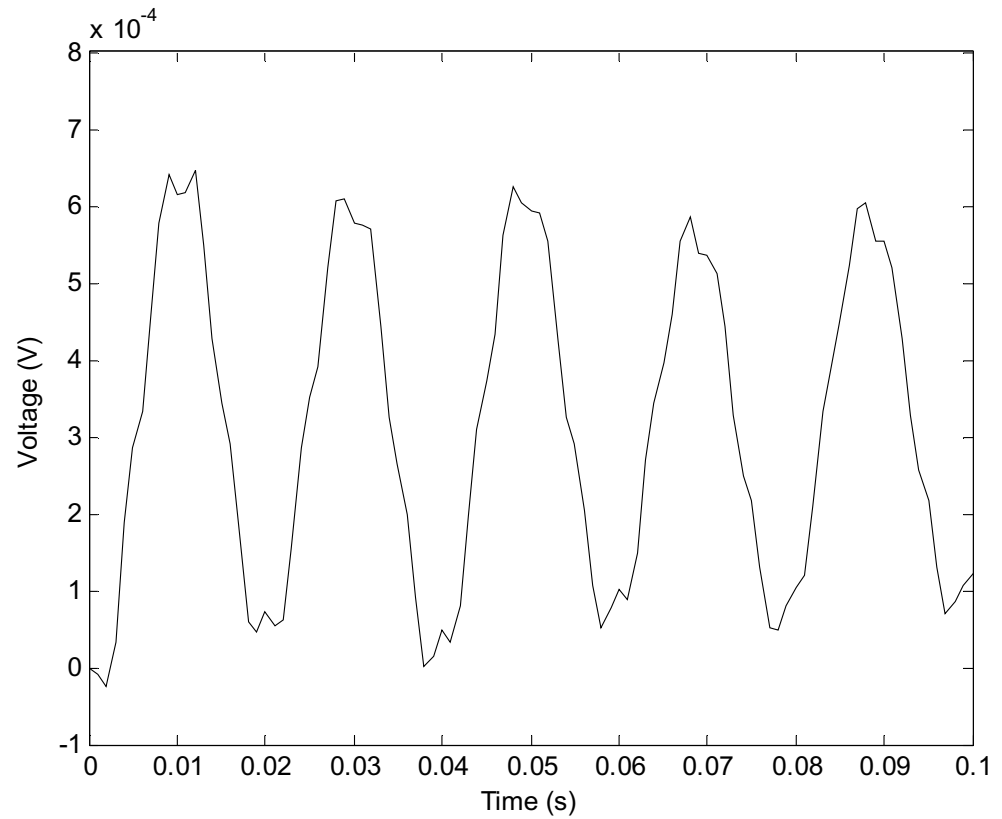

Fig. 5. PZT sensor voltage for the non-rotating system. An upward step force is acting at the tip of the blade where PZT sensor is mounted.

The PZT is attached to the root of the blade applying the same step input for the $20 \mathrm{~Hz}$ rotating system, and the time and frequency responses for the PZT voltage are shown in Figs 7 and 8. The PZT spectrum, Fig. 8, shows components at about 58, 110 and $260 \mathrm{~Hz}$ frequencies. The PZT voltage time and frequency plots for the $40 \mathrm{~Hz}$ rotating speed are given in Figs 9 and 10.

It is clear in these figures that the PZT sensor is able to sense the $1^{\text {st }}$ natural frequency of the blades corresponding to the bending. The $2^{\text {nd }}$ blade bending frequency around $260 \mathrm{~Hz}$ is also distinguishable in the sensor frequency plots. 


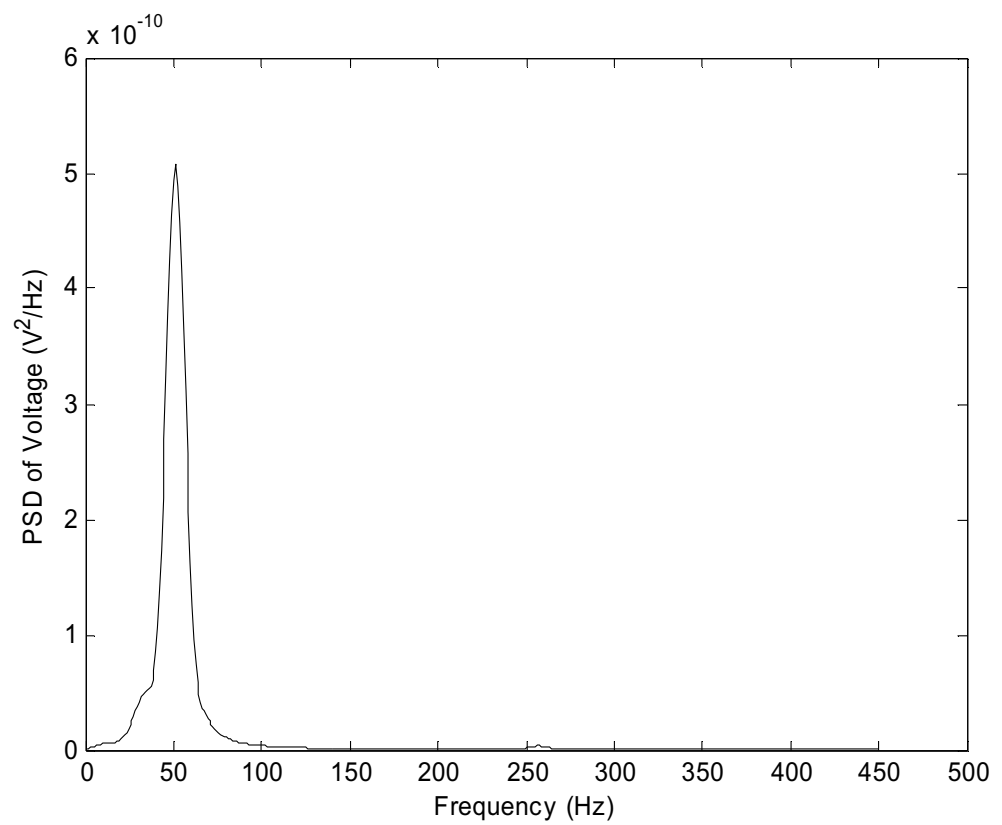

Fig. 6. Frequency spectrum of the PZT sensor voltage of Fig. 5.

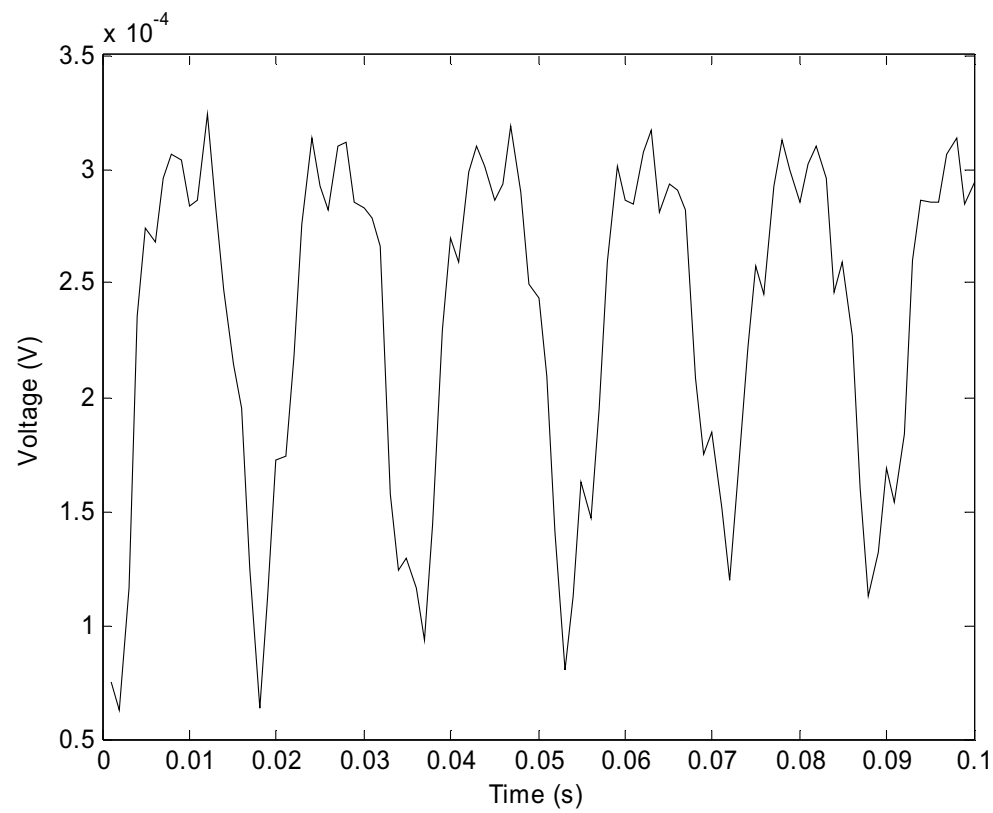

Fig. 7. PZT sensor voltage for the system rotating at $20 \mathrm{~Hz}$. An upward step force is acting at the tip of the blade where PZT sensor is mounted.

\subsubsection{Step input at opposite blade}

To examine the sensitivity of the PZT sensor, the blade opposite to the one with the embedded PZT sensor is excited by a similar step force. The PZT voltage signal for the non-rotating system is shown in Fig. 11. The associated frequency spectrum is given in Fig. 12, which shows vibrations at the rigid body mode $(28 \mathrm{~Hz})$, at the blade's first bending natural frequency $(52 \mathrm{~Hz})$ and at $260 \mathrm{~Hz}$. The blade's first bending natural frequency has the highest amplitude among these frequency components. With these responses one can observe that the PZT sensor is 


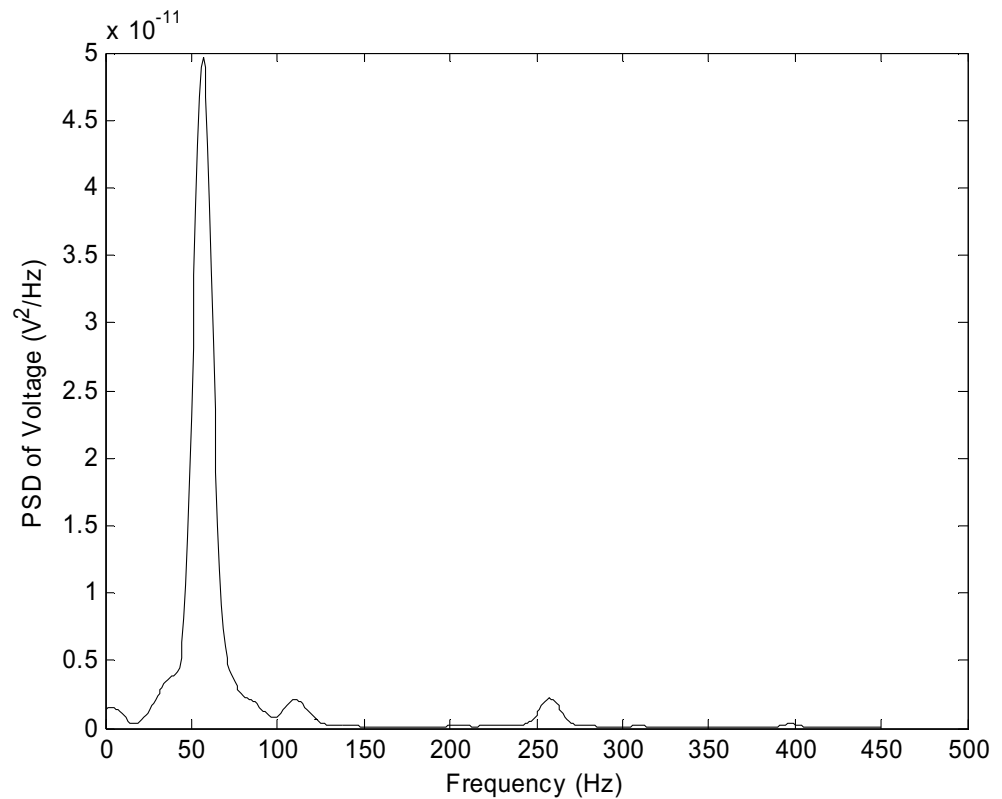

Fig. 8. Frequency spectrum of the PZT sensor voltage of Fig. 7.

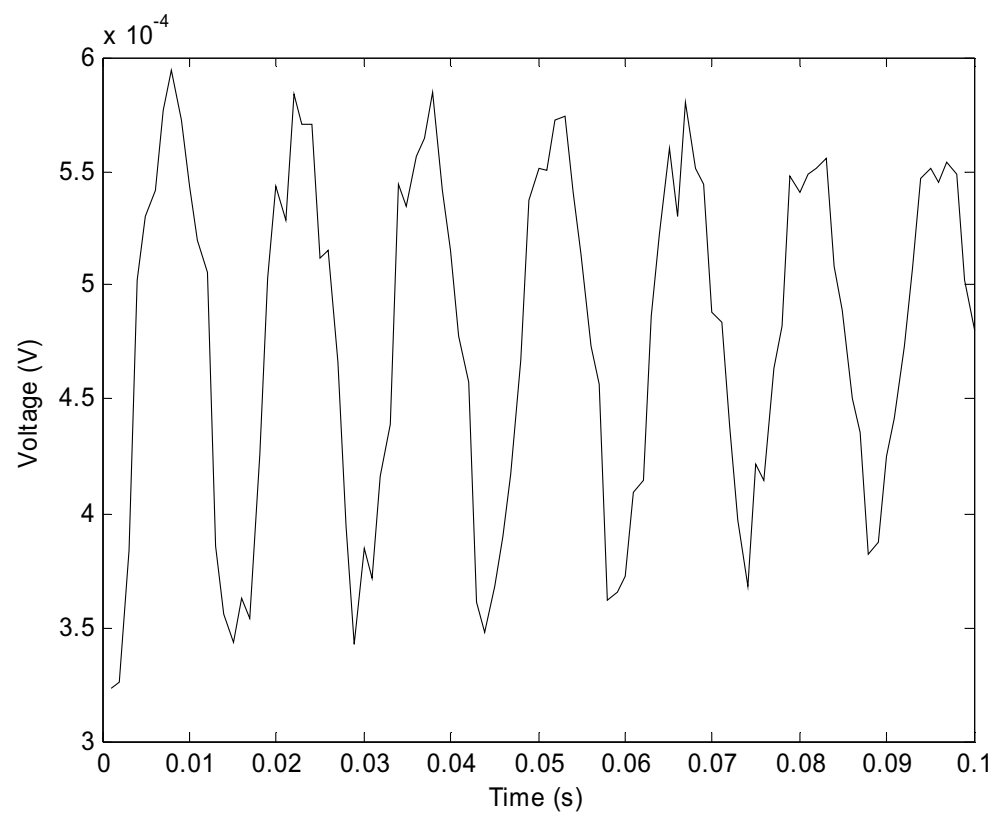

Fig. 9. PZT sensor voltage for the system rotating at $40 \mathrm{~Hz}$. An upward step force is acting at the tip of the blade where PZT sensor is mounted.

not only sensitive to the blade under which it is embedded but also to other blades through the motion transmitted by the disk. This explains the excitation of the rigid body and second bending modes due to blade excitations through their base, which can induce parametric vibrations at the second mode. Since the parametric excitation is rotating speed dependent, this explains the similar behavior presented in the previous section.

Figures 13 through 16 display the time and frequency results for the cases when the rotor is rotating. It is easy to see in these figures the sensor's capacity in sensing the blade vibrations. As mentioned above, the first bending mode of blades is dominant, but the $2^{\text {nd }}$ bending frequency about $260 \mathrm{~Hz}$ is also noticed in all the frequency plots. 


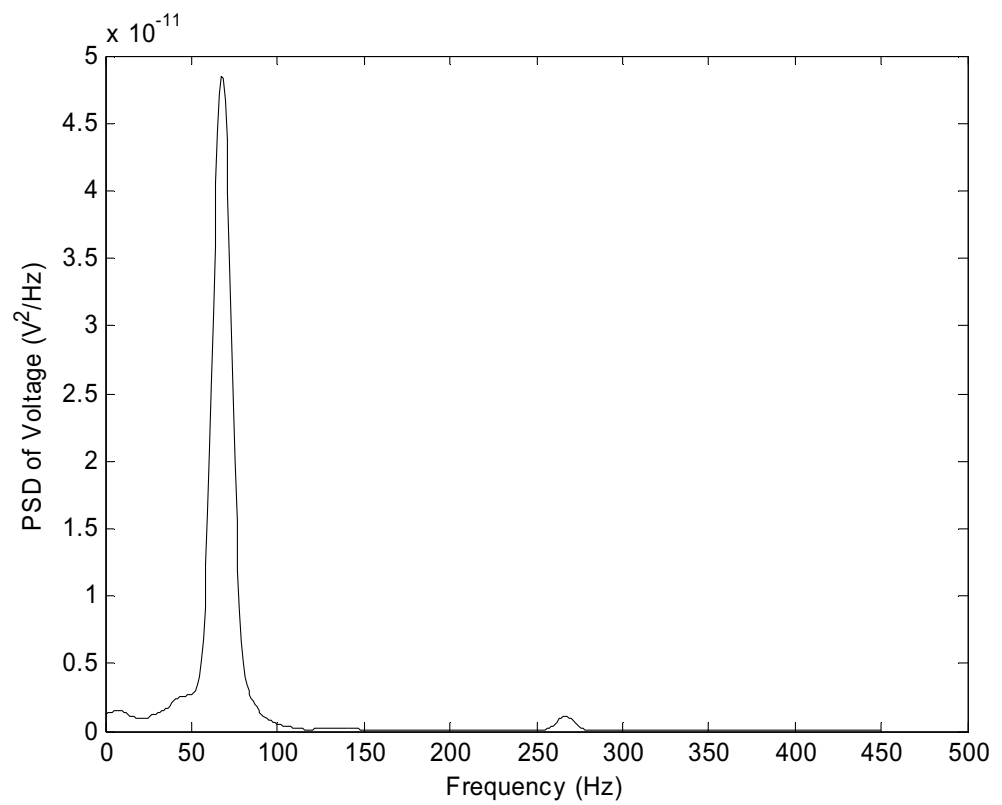

Fig. 10. Frequency spectrum of the PZT sensor voltage of Fig. 9.

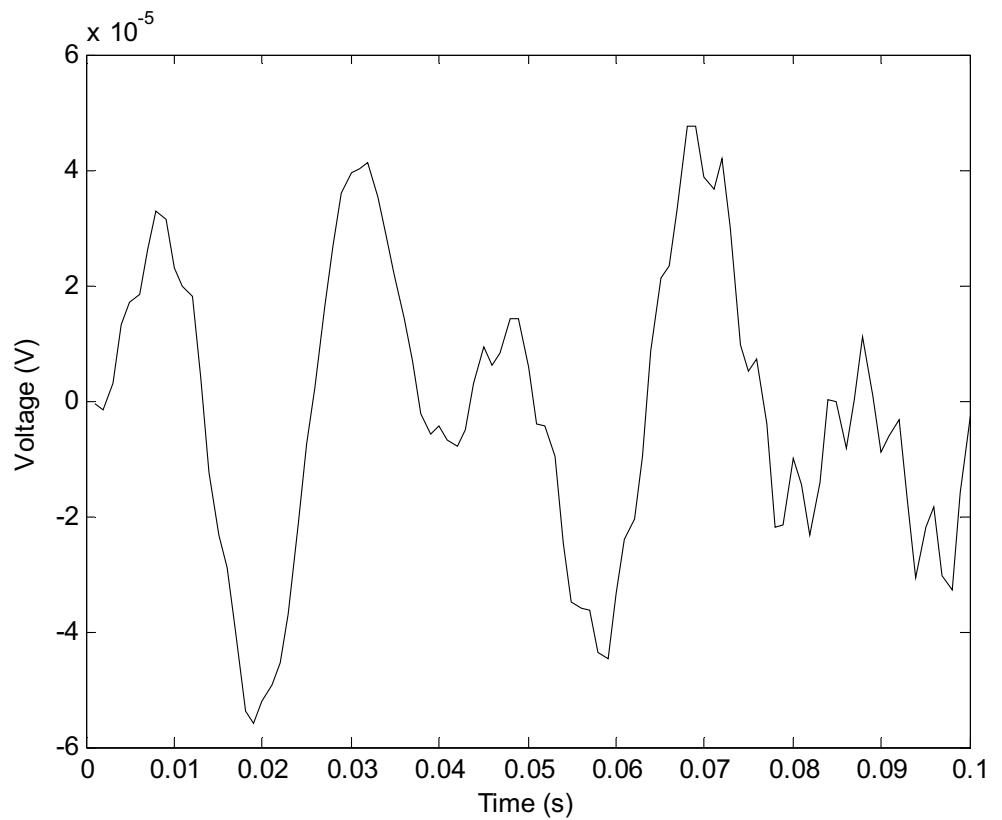

Fig. 11. PZT sensor voltage for the non-rotating system. An upward step force is acting at the tip of the opposite blade.

It is interesting to note that the rigid body mode for the rotation of the system about the shaft axis is sensed by the PZT transducer when the system is not rotating (Fig. 12), but this mode diminishes at the higher speeds (Figs 14 and 16).

\subsubsection{Rubbing}

Another type of loading sometimes experienced in practice is when the blade(s) are rubbing to the stator or casing. This loading condition is simulated to find out the PZT material behavior. The rubbing is simulated for the $40 \mathrm{~Hz}$ 


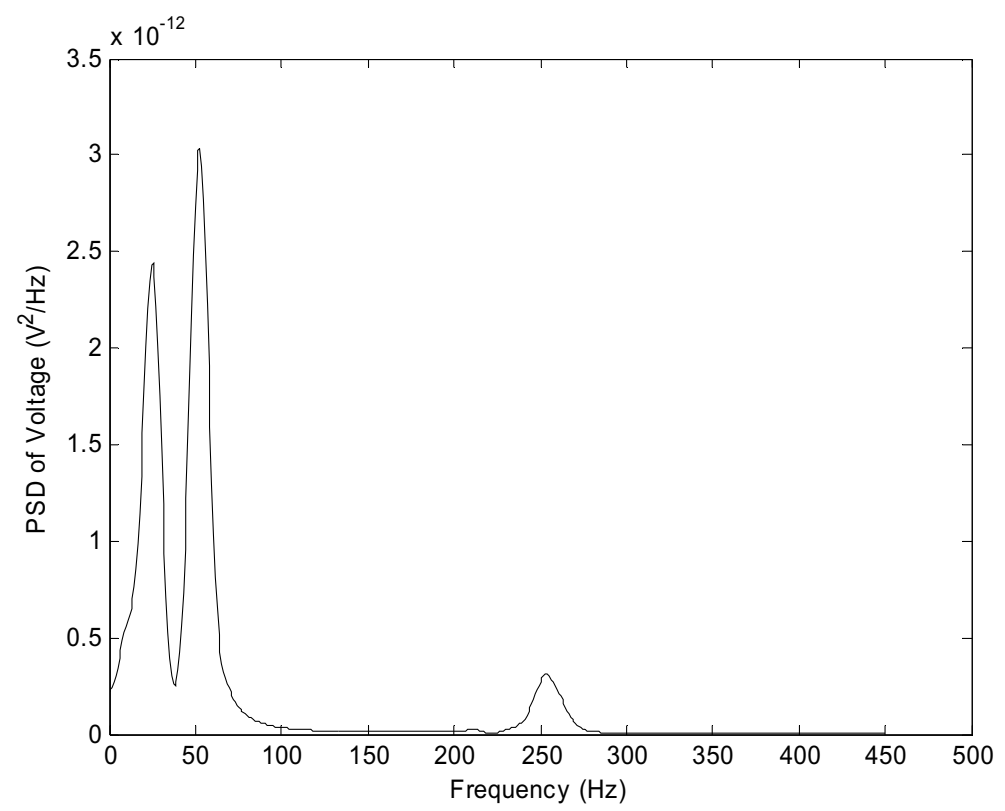

Fig. 12. Frequency spectrum of the PZT sensor voltage of Fig. 11.

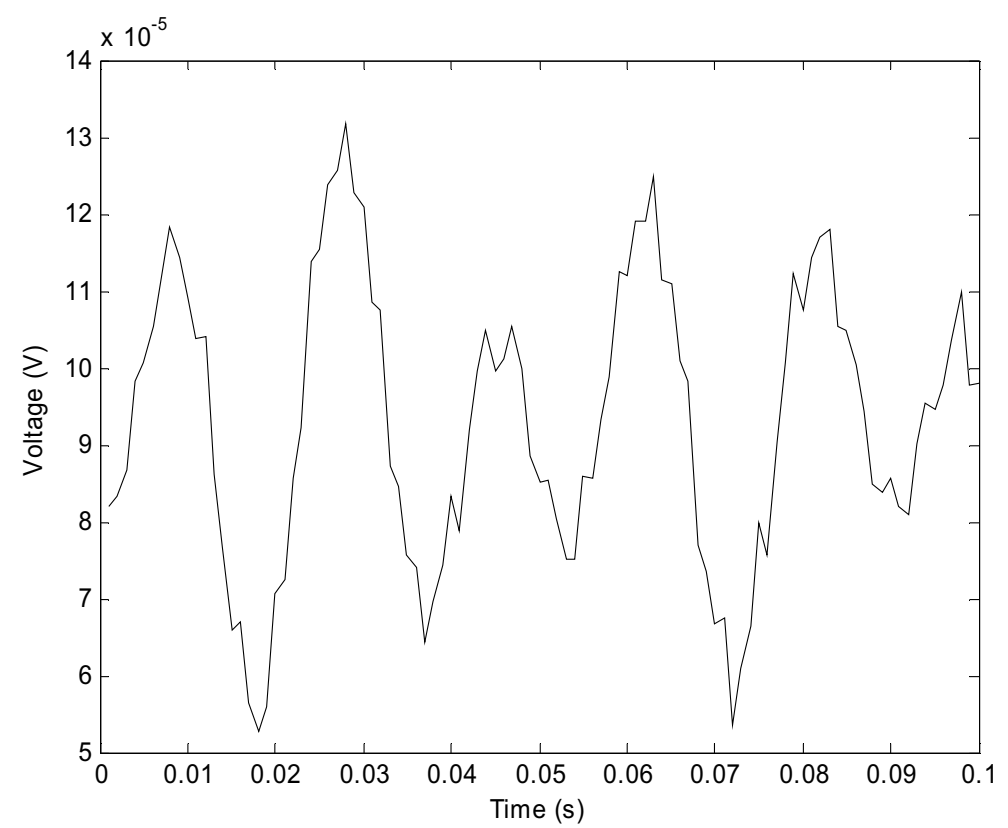

Fig. 13. PZT sensor voltage for the system rotating at $20 \mathrm{~Hz}$. An upward step force is acting at the tip of the opposite blade.

rotating speed and the time of rubbing contact is estimated based on the number of blades and the speed of rotation as $2.08 \times 10^{-4}$ seconds. During the rubbing duration normal and tangential forces are applied. The normal force is $F_{N}=k_{s} \delta$ and the tangential force is $F_{T}=\mu_{f} F_{N}$. The data, based on a previous study by Al-Bedoor [21], suggests that $k_{s}=10^{7}, \delta=8.675 \times 10^{-7} \mathrm{~m}$ and $\mu_{f}=0.2$, and therefore $F_{N}=8.675 \mathrm{~N}$ and $F_{T}=1.735 \mathrm{~N}$. The time and frequency plots for the resulting PZT sensor voltage are shown in Figs 17 and 18. Vibrations at the blade first bending frequency can be easily noticed in the PZT sensor's frequency spectrum in addition to vibrations at 


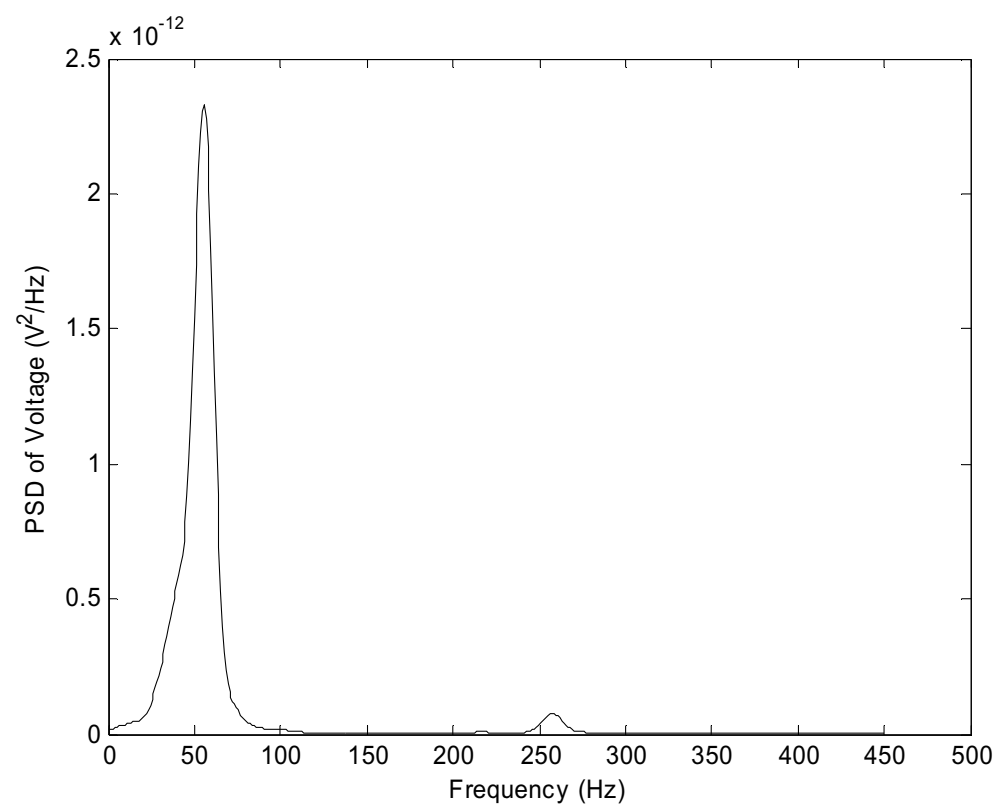

Fig. 14. Frequency spectrum of the PZT sensor voltage of Fig. 13.

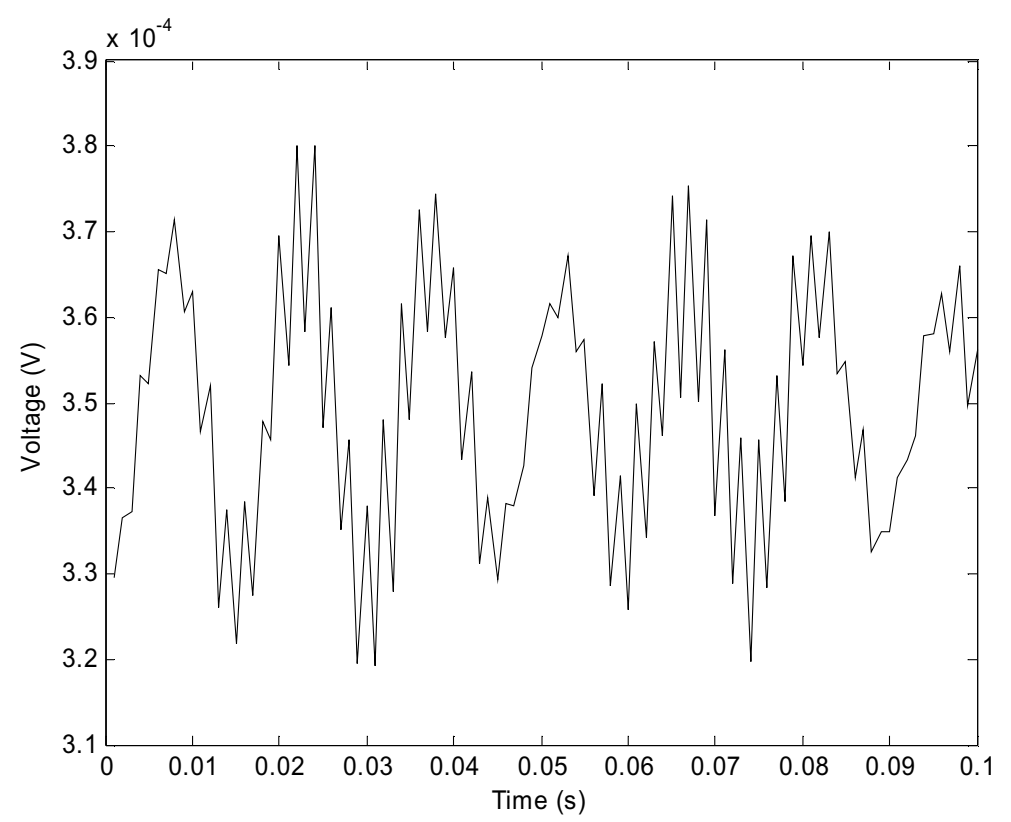

Fig. 15. PZT sensor voltage for the system rotating at $40 \mathrm{~Hz}$. An upward step force is acting at the tip of the opposite blade.

$180 \mathrm{~Hz}$ and $260 \mathrm{~Hz}$ frequencies with less amplitudes. The PZT voltage reflects rather the vibrations at the root node as expected.

\subsubsection{White noise excitation}

To explore more the PZT response to a signal rich with frequencies, a frequently-used approach, the tip of the blade with root embedded PZT material is acted upon by a white noise signal, whose PSD is constant of $3 \mathrm{~N}^{2} / \mathrm{Hz}$ over the frequency range from $20 \mathrm{~Hz}$ to $400 \mathrm{~Hz}$. The vibration spectrum of the PZT signal is shown in Fig. 19. The 


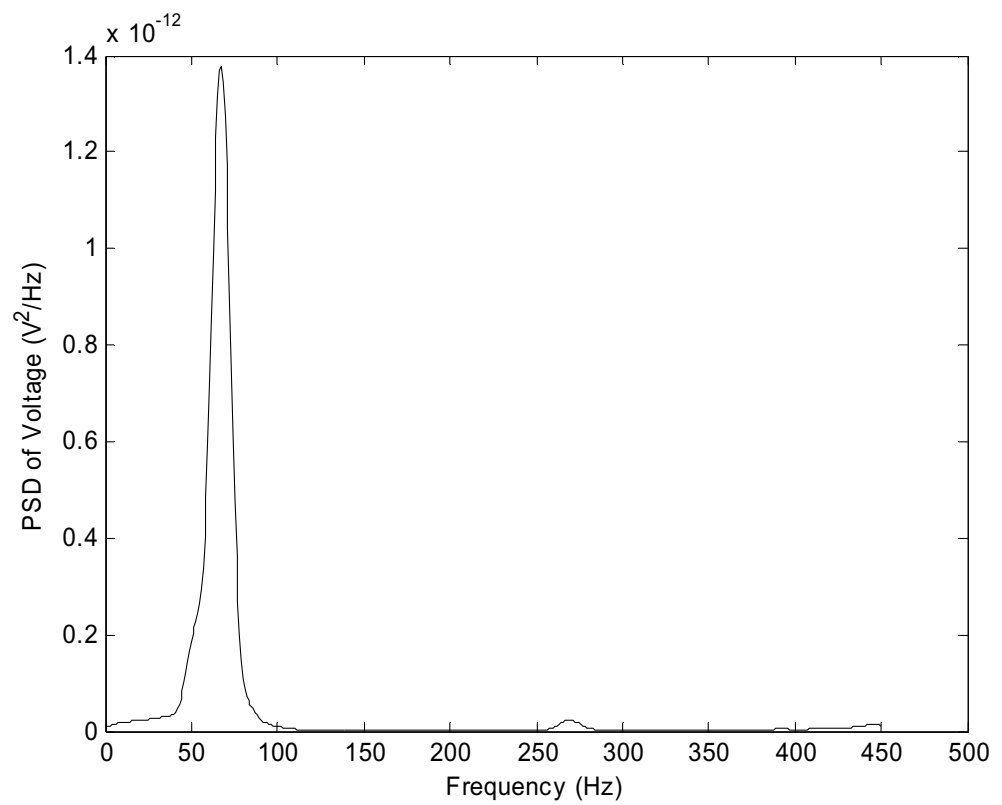

Fig. 16. Frequency spectrum of the PZT sensor voltage of Fig. 15.

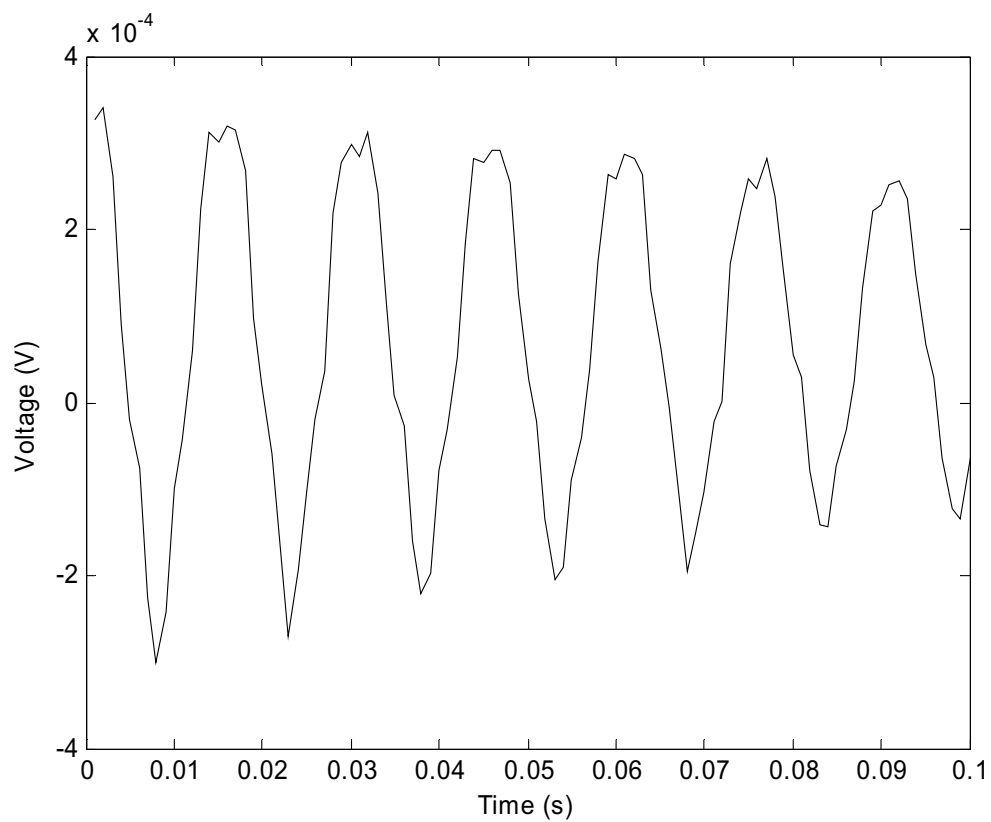

Fig. 17. PZT sensor voltage for the system rotating at $40 \mathrm{~Hz}$. Rubbing is assumed at the tip of the blade where PZT sensor is mounted.

PZT sensor voltage has captured frequency components at $40 \mathrm{~Hz}, 52 \mathrm{~Hz}$ and $340 \mathrm{~Hz}$ with more sensitivity to the 340 $\mathrm{Hz}$ component. This has occurred as the sensor efficiently reflects the motion at the blade tip.

\subsection{Steady-state response}

Major part of rotating blade excitation occurs due to rotor unbalance, misalignment and/or blade pass frequency excitation. These forces are mainly characterized by harmonic excitation at the running speed and its harmonics. 


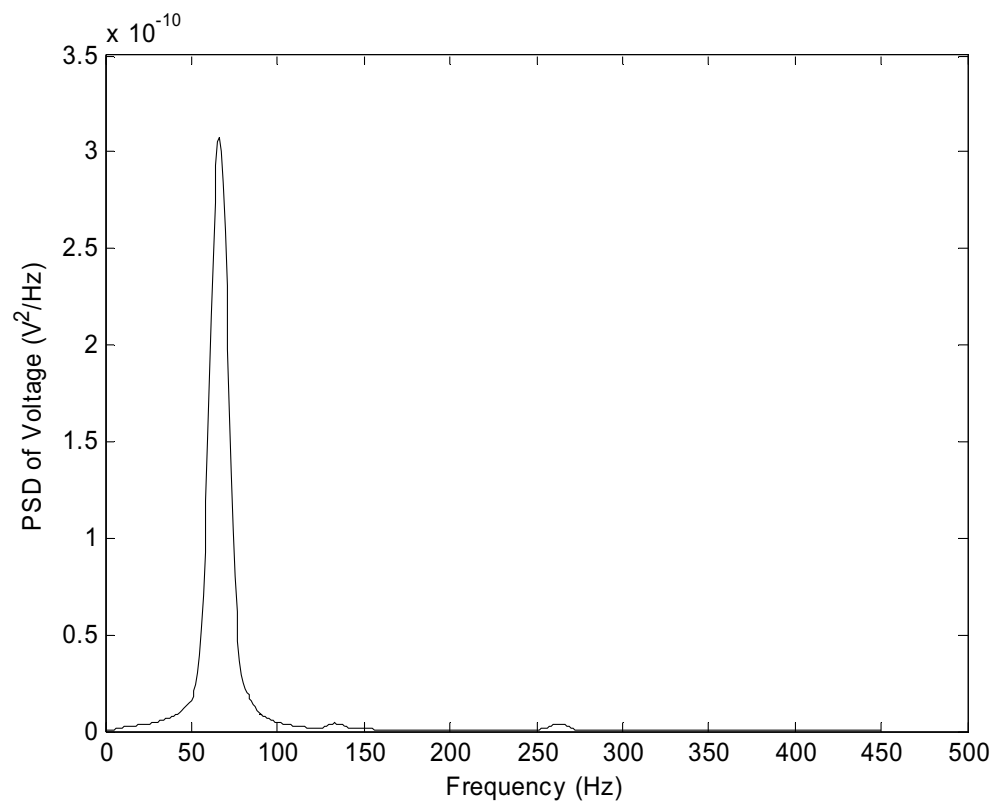

Fig. 18. Frequency spectrum of the PZT sensor voltage of Fig. 17.

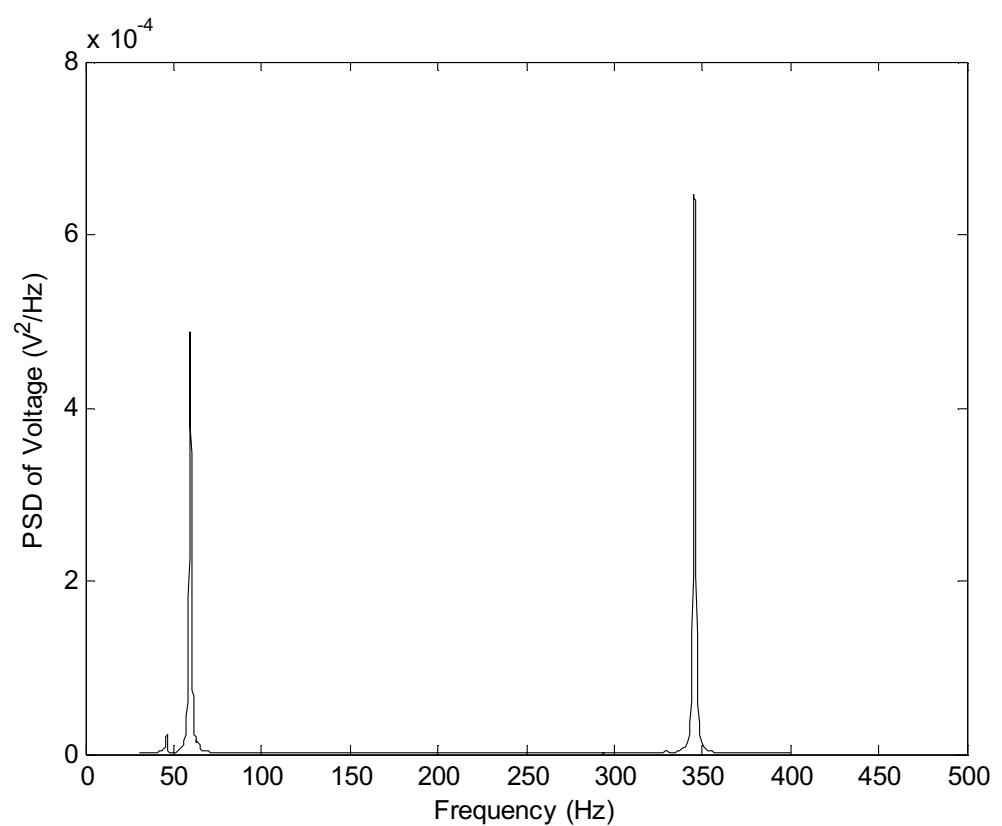

Fig. 19. PZT sensor voltage for the system rotating at $40 \mathrm{~Hz}$. A vertical step force of white noise is acting at the tip of the blade where PZT sensor is mounted.

To simulate such excitation conditions a sinusoidal tip force of magnitude $1.735 \mathrm{~N}$ is applied. The frequency of the force is equal to the rotating speed (i.e. 1X excitation) for the speeds of 20 and $40 \mathrm{~Hz}$. The waveforms for the blade tip displacement and PZT voltage signal together with their frequency spectrums are shown in Figs 20 and 21. It can be observed that the PZT sensor voltage outputs have captured the vibrations at the steady-state excitation frequencies. However, for higher speeds low frequency components can be observed in the voltage spectrum, which can be related to excitation of the blade base due to incoming motion from the free vibrations of the other blades 

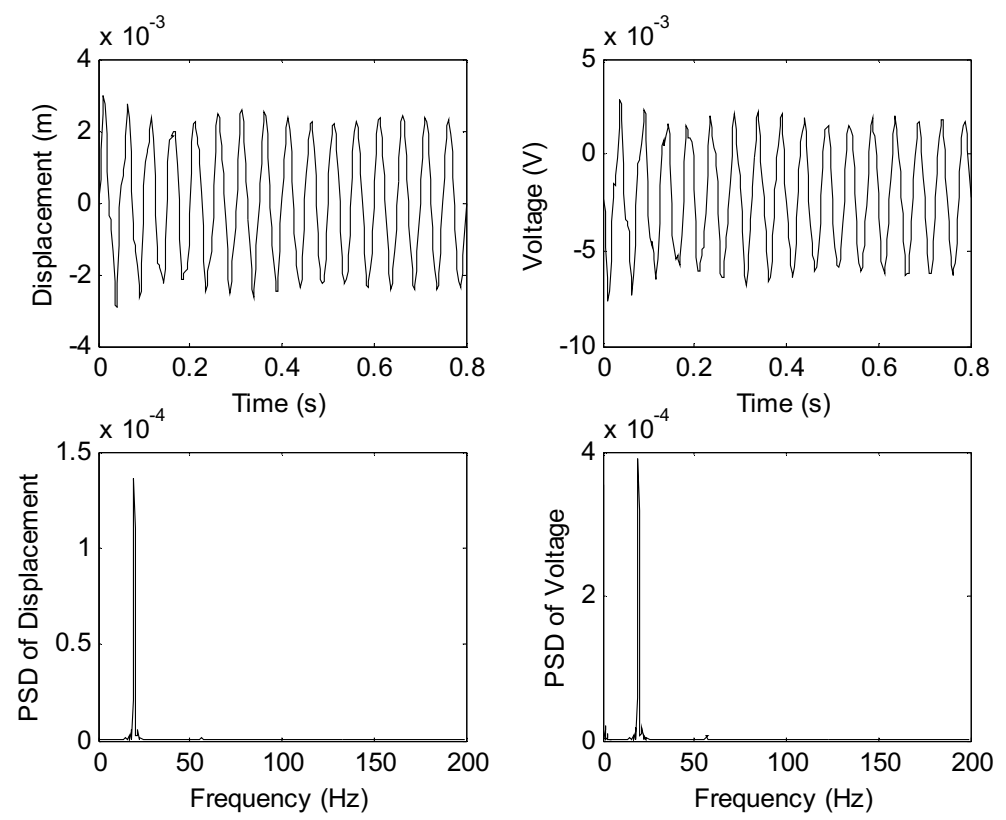

Fig. 20. Steady-state time history and frequency spectrum plots for vertical blade tip displacement and PZT sensor voltage at $f=20$ Hz. A sinusoidal vertical step force of $20 \mathrm{~Hz}$ is acting at the tip of the blade where PZT sensor is mounted.
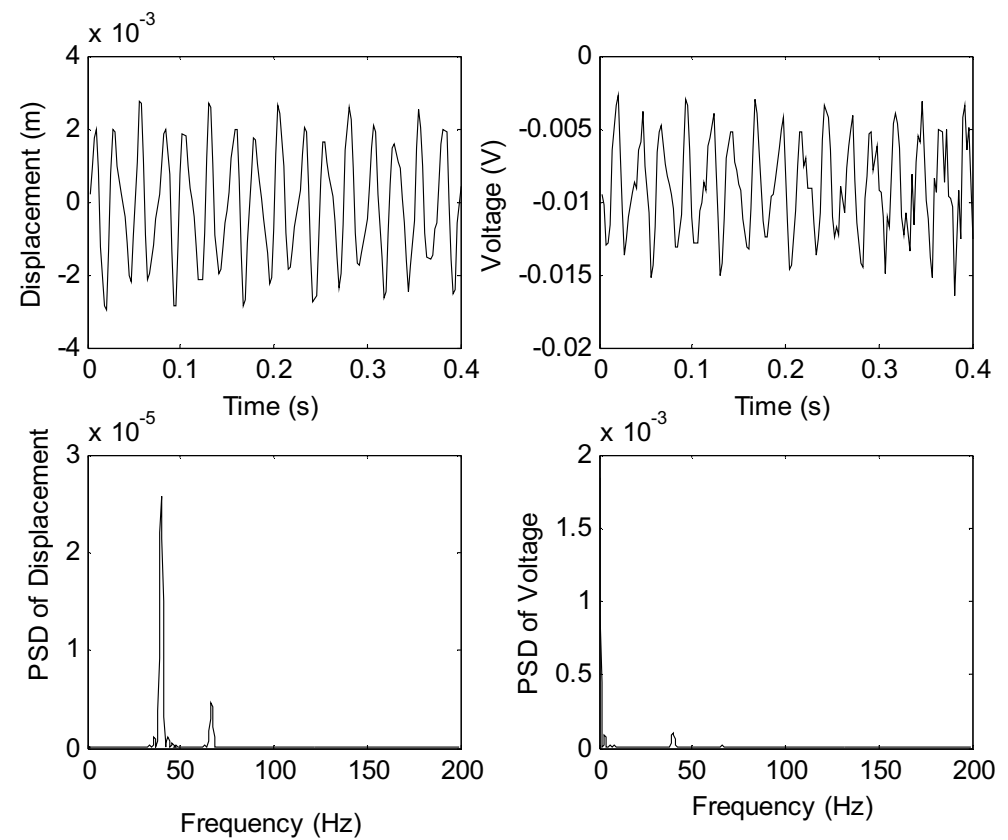

Fig. 21. Steady-state time history and frequency spectrum plots for vertical blade tip displacement and PZT sensor voltage at $f=40 \mathrm{~Hz}$. A sinusoidal vertical step force of $40 \mathrm{~Hz}$ is acting at the tip of the blade where PZT sensor is mounted.

that can occur due to torsional vibrations.

To further investigate the blade vibrations, for the system rotating at $20 \mathrm{~Hz}$, sinusoidal forces at the middle and tip of the blade with frequencies of $20 \mathrm{~Hz}$ and $100 \mathrm{~Hz}$ are applied, respectively. The blade tip deflection and the sensor voltage output are shown in Fig. 22. The blade vibrates at the two frequencies of $20 \mathrm{~Hz}$ and $100 \mathrm{~Hz}$ in addition to 

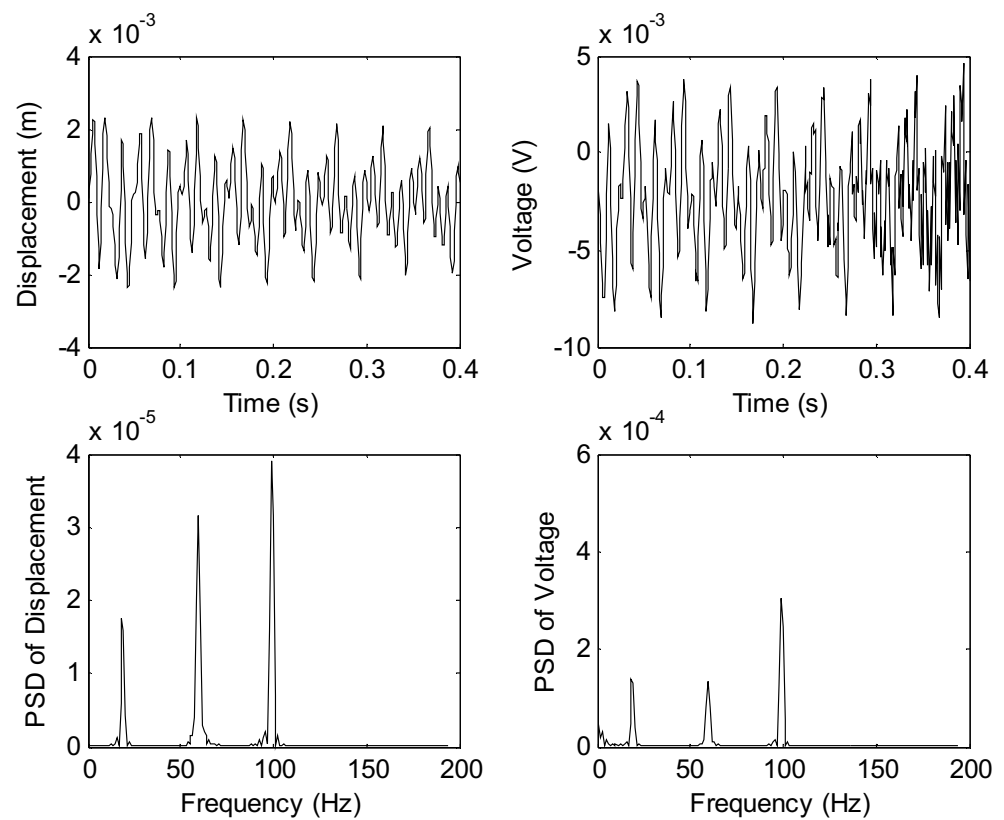

Fig. 22. Steady-state time history and frequency spectrum plots for vertical blade tip displacement and PZT sensor voltage at $f=20 \mathrm{~Hz}$. Sinusoidal vertical step forces are acting in the middle and at the tip of the blade with respective frequencies of $20 \mathrm{~Hz}$ and $100 \mathrm{~Hz}$.
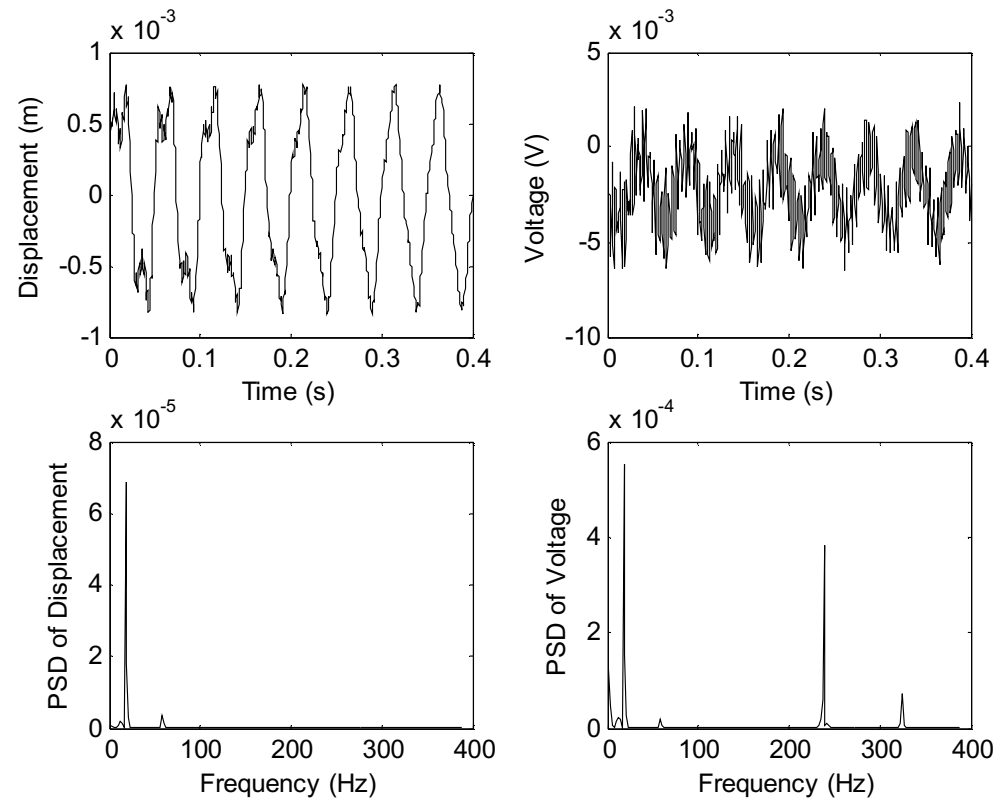

Fig. 23. Steady-state time history and frequency spectrum plots for vertical blade tip displacement and PZT sensor voltage at $f=20 \mathrm{~Hz}$. Sinusoidal vertical step forces are acting in the middle and at the tip of the blade with respective frequencies of $20 \mathrm{~Hz}$ and $240 \mathrm{~Hz}$.

its own natural frequency of $52 \mathrm{~Hz}$. To simulate blade pass frequency the middle of the blade is excited at $20 \mathrm{~Hz}$ and the tip at $20 \times 12=240 \mathrm{~Hz}$. The tip deflection and sensor voltage signal are shown in Fig. 23, wherein again excellent representation is evident by the PZT voltage signal. 


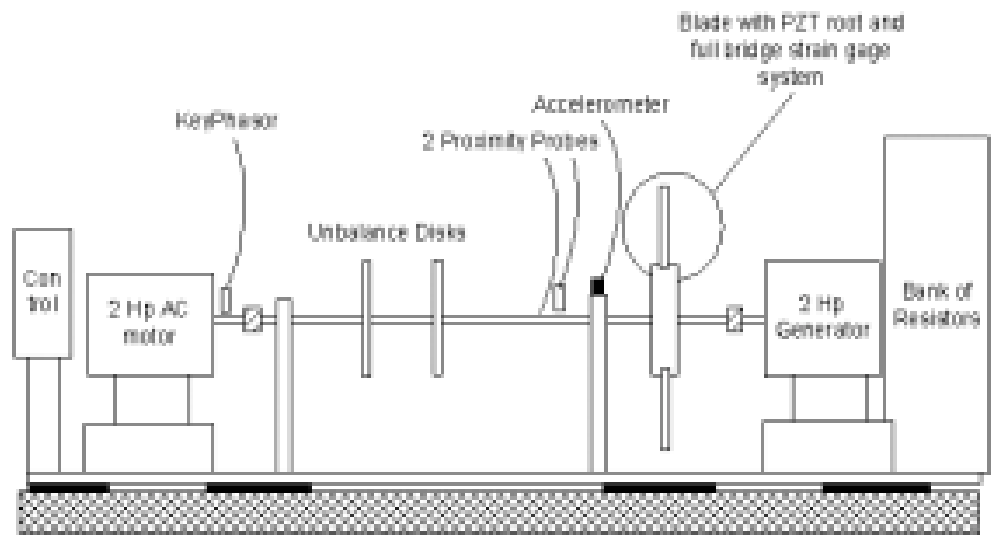

Fig. 24. Schematic of the test-rig.

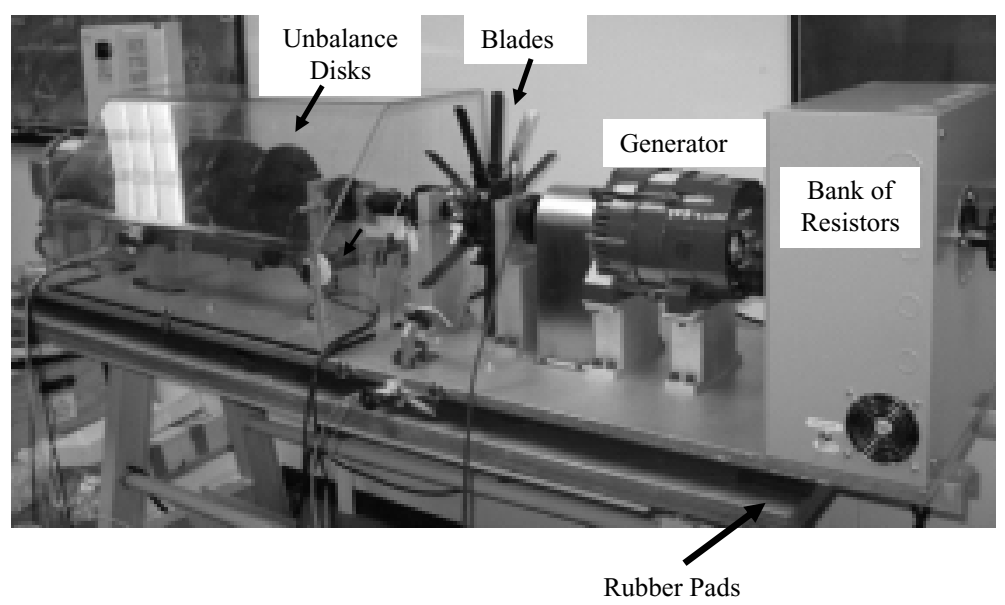

Fig. 25. Photograph of the test-rig.

\section{Experimental part}

\subsection{Test-rig and blade-PZT root design}

The test-rig used for the measurement of rotating blade vibration consists of a $2 \mathrm{hp} \mathrm{AC} \mathrm{motor} \mathrm{with} \mathrm{a} \mathrm{speed}$ controller, two unbalance disks, a disk holding 12 blades, a $2 \mathrm{hp}$ generator and a bank of resistors to impose electrical load on the rotor. The schematic and the photograph of the test-rig are shown in Figs 24 and 25, respectively.

The blades are made of commercial steel with dimensions of $100 \times 25.4 \times 1 \mathrm{~mm}$. To securely hold the PZT material in its place and to prevent it from breaking due to centrifugal effects, a holder was redesigned with an edge that holds the material also in the radial direction (Fig. 26). The photograph of the holder and the blade assembled to the disk of the test-rig is shown in Fig. 27.

\subsection{Instrumentation and signal processing}

With the objective of evaluating the blade vibration signal obtained from the root-embedded PZT material, a system of vibration measurement was designed. As shown in Figs 1 and 2, the vibration measurement system consists of a keyphasor, vertical and horizontal proximity probes, an accelerometer, a strain gage system and a PZT block. However, due to the lack of space, only the results of the strain gage system and the PZT material are provided and discussed. 


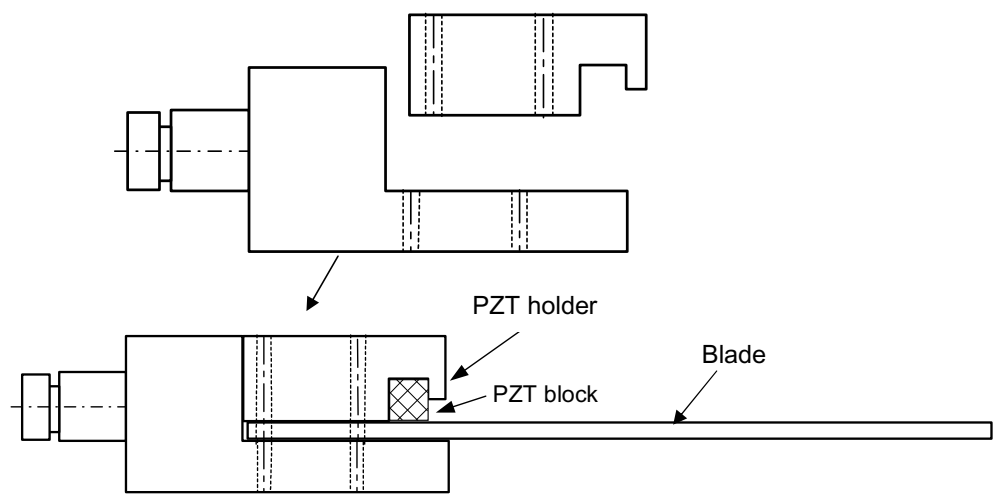

Fig. 26. Blade-PZT root holder.

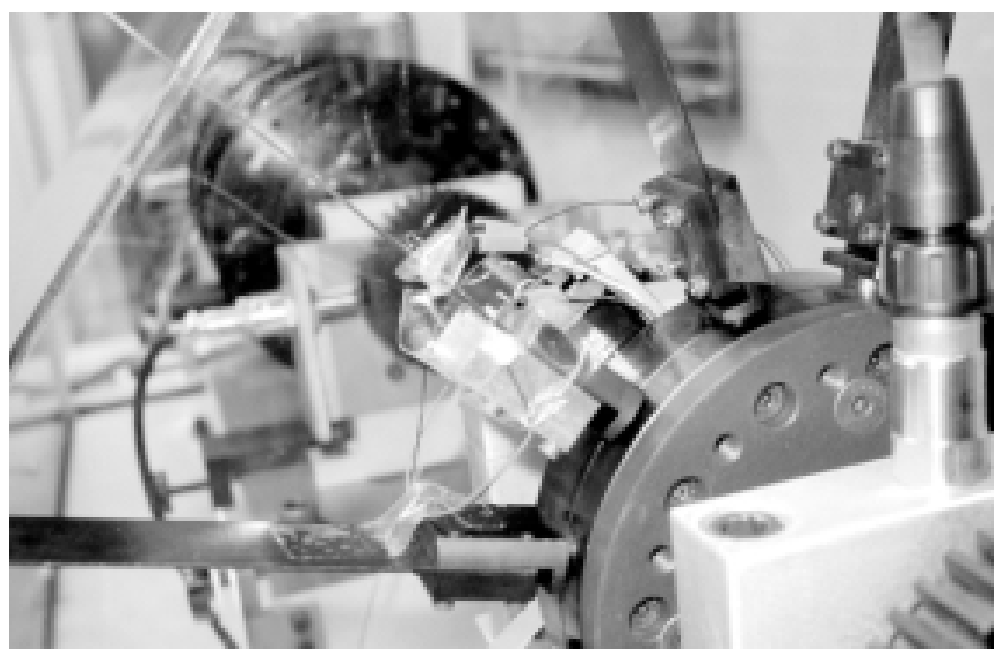

Fig. 27. Photograph of the blade-PZT root holder.

The blade is equipped with standard $350 \mathrm{Ohm}$ strain gages in full bridge, which are powered by $9 \mathrm{~V}$ DC batteries from the Binsfeld transmitter. The transmitter has a built-in amplifier that enables amplifying the strain gage output signal before transmitting it to the receiver antenna. The blade with strain gages was calibrated and the system scale factor was found to be $0.75 \mathrm{mV} / \mathrm{mm}$. The voltage signal from the PZT material is also taken to the Binsfeld transmitter which transmits the signal to the stationary receiver.

A schematic of the five channel vibration measurement system is shown in Fig. 28. The signals from the strain gages and the PZT block are taken using the wireless Binsfeld 9000 TorqueTrak system at two different frequency paths. The rotating parts of the wireless system have built-in amplifiers with selectable gains that were set as 250 and 400 for the PZT and the strain gage outputs, respectively. The five channel signals are fed to the data acquisition system BNC DAIU208P that gives its output to the computer to perform the signal processing using the ADRE rotating machinery data analysis software.

\subsection{Experimental results and discussion}

To investigate the applicability of using the root-embedded PZT material for the blade vibration measurements, a number of experiments were conducted on the available test rig, which were classified into three groups:

1. Free vibration testing.

2. Steady state vibration testing of different speeds. 


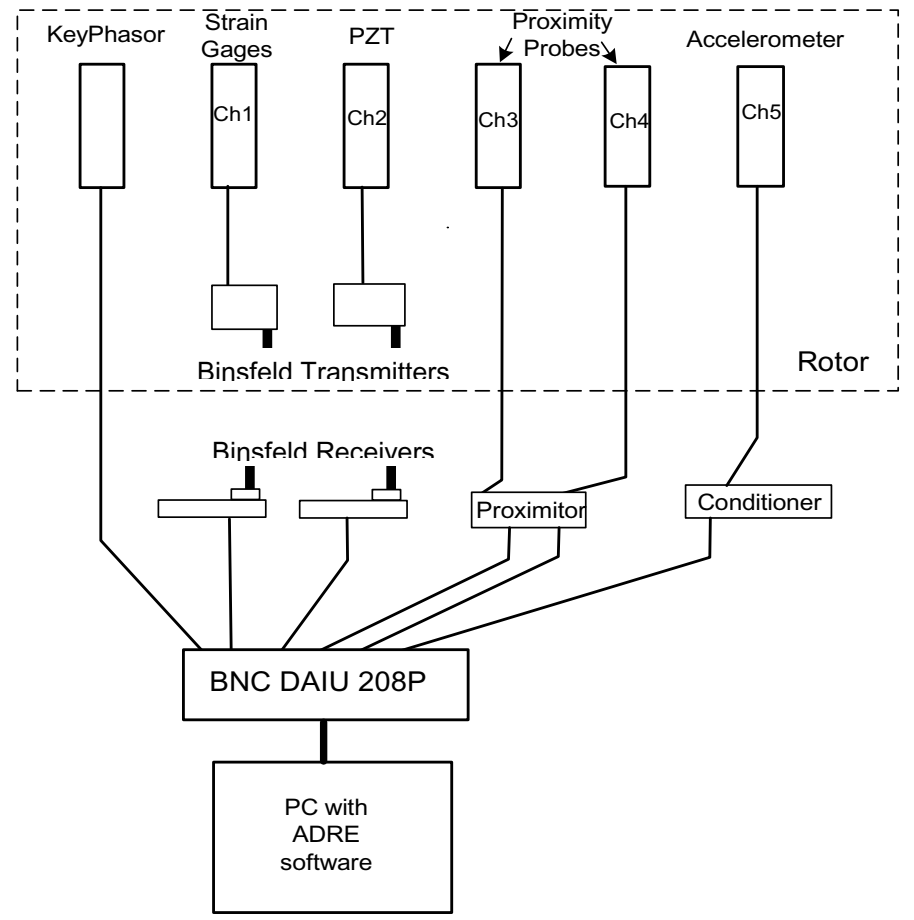

Fig. 28. Schematic of the vibration measurement system.

\section{Steady state vibration testing with blades-to-stator rubbing.}

In all frequency spectrums the frequency range from 0 to $500 \mathrm{~Hz}$ is selected as no frequency components of noticeable amplitude were observed in signals above the $500 \mathrm{~Hz}$ cut off. The signal coming from the strain gage system will be considered as the signal representing the actual blade vibrations, since it seems to be the most successful method so far for the blade vibration measurements.

\subsubsection{Free vibrations}

The free vibration test is conducted to check the sensitivity of the embedded PZT material and to compare its produced signals to those obtained from the strain gages. The free vibration was initiated by giving the blade under which the PZT material is embedded and which is equipped with full-bridge strain gages a tip deflection of about $0.5 \mathrm{~cm}$. The signals collected by the strain gages and PZT material were processed and their associated frequency spectrums are presented in Figs 29 and 30. Before discussing the details of frequency spectrum contents, it is note worthy to mention that in such a rotating system there are usually modes with contributions from the shaft, disk and blades. In other words the individual modes of the blades and shaft lateral and torsional vibrations are expected to be mixed and their frequencies would be different if these components were analyzed as separate components.

The frequency spectrum of the strain gage signal is shown in Fig. 29. Distinct frequencies of $2 \mathrm{~Hz}, 38 \mathrm{~Hz}, 50 \mathrm{~Hz}$, $225 \mathrm{~Hz}$ and $250 \mathrm{~Hz}$ are apparent in the spectrum. The highest amplitude appears for the $2 \mathrm{~Hz}$ component which can be related to the rigid body and torsional vibration modes that produced a free rotation when the blade was excited. The $38 \mathrm{~Hz}$ component can be related to the shaft lateral vibration mode as this frequency component was also found in the vertical proximity probe signal spectrum (not shown here). The $50 \mathrm{~Hz}$ component is the blade(s) first bending natural frequency which is close to the $52 \mathrm{~Hz}$ frequency obtained by the finite element analysis in Part 1 . The $225 \mathrm{~Hz}$ component can be linked to the shaft bearing system natural frequencies.

The frequency spectrum of the embedded PZT material signal is shown in Fig. 30. The PZT spectrum indicates frequency components of $2 \mathrm{~Hz}, 38 \mathrm{~Hz}, 50 \mathrm{~Hz}, 225 \mathrm{~Hz}, 252 \mathrm{~Hz}, 325 \mathrm{~Hz}$ and $450 \mathrm{~Hz}$. Some components given by the PZT signal are the same given by the strain gage spectrum of Fig. 29 with same relative sensitivities between different components. The higher frequencies given by the PZT spectrum, $325 \mathrm{~Hz}$ and $450 \mathrm{~Hz}$, can be related to the 


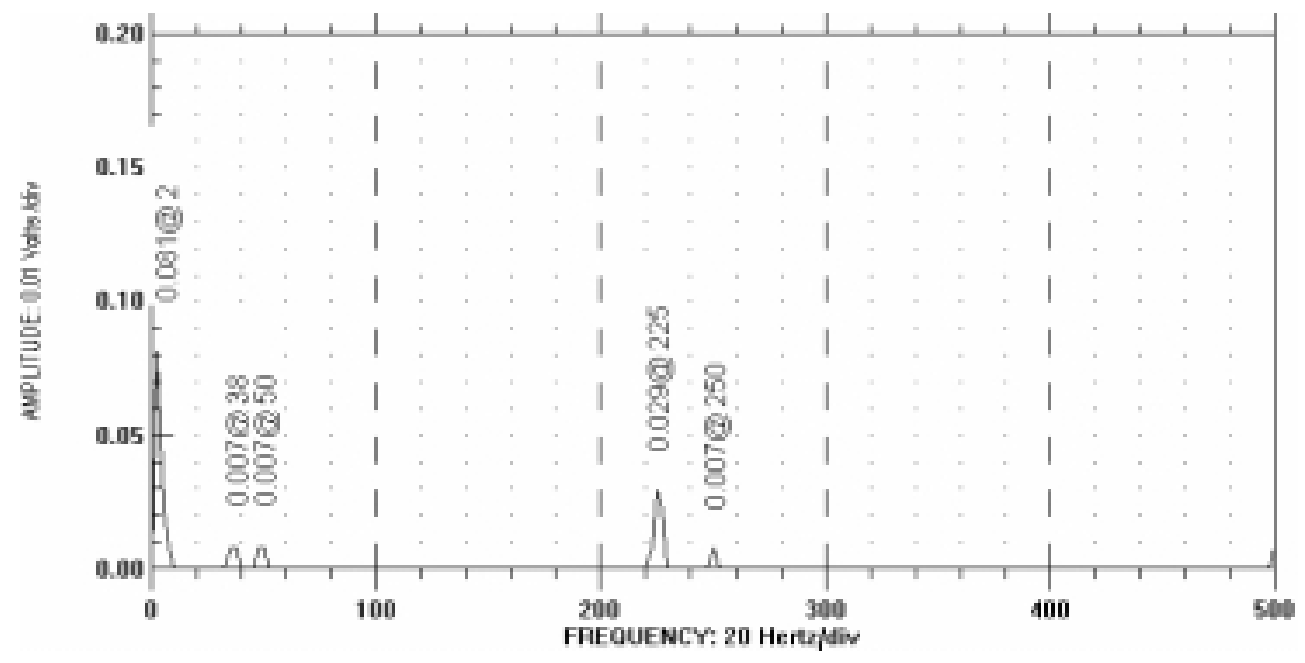

Fig. 29. Frequency spectrum of the strain gage signal for the free vibration test.

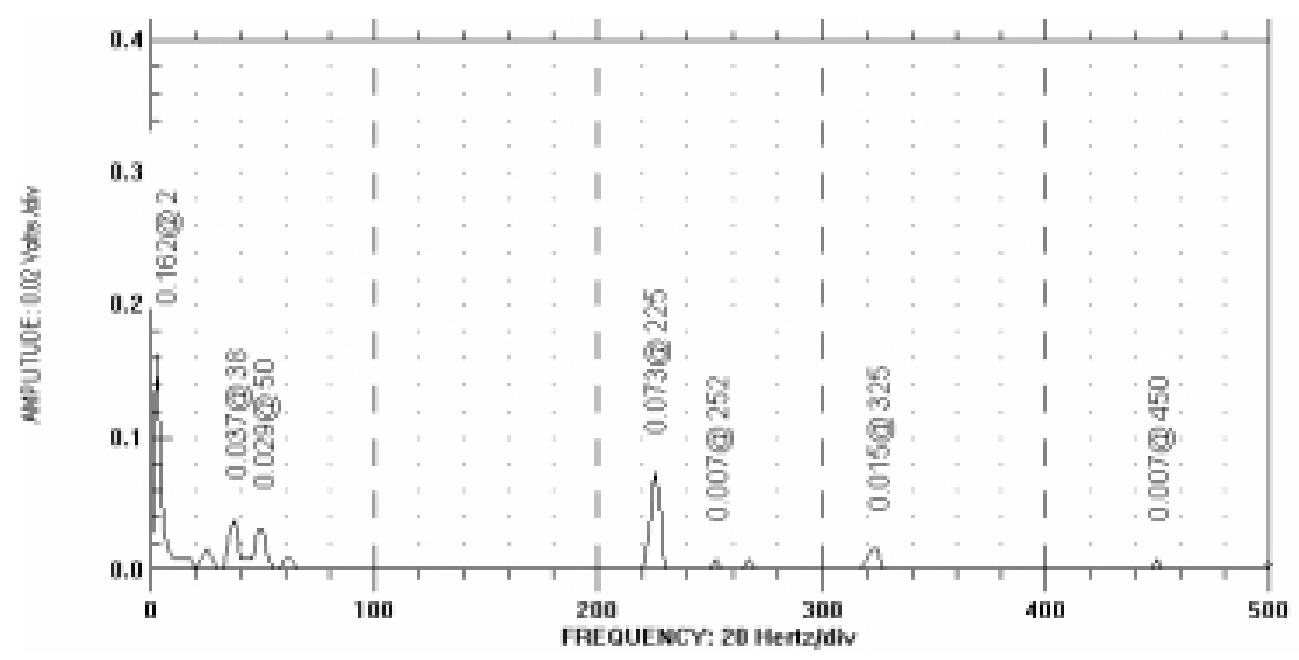

Fig. 30. Frequency spectrum of the PZT signal for the free vibration test.

second bending mode of the blade and higher mode of the shaft-bearing system, respectively. The $325 \mathrm{~Hz}$ component has also appeared in the previous finite element analysis part.

Considering the above discussions on the spectrums from the free vibration test and having in mind that the objective is not to identify the different frequencies appeared but to examine the PZT signal for its representation of the blade vibrations, one can come out with the following points:

1. The blade vibration response to initial tip deflection is characterized by rigid body/torsional vibration at frequency of $2 \mathrm{~Hz}$, vibration at its own first bending natural frequency of $50 \mathrm{~Hz}$, vibration at the shaft lateral natural frequency of $38 \mathrm{~Hz}$ and vibrations at $225 \mathrm{~Hz}$ and $250 \mathrm{~Hz}$.

2. The PZT material signal captured all the frequency components captured by the strain gage signal with even higher amplitudes. More frequency components are captured by the PZT signal than the strain gage signal, which are $325 \mathrm{~Hz}$ and $450 \mathrm{~Hz}$.

3. The rigid body mode at $2 \mathrm{~Hz}$ can be related to the torsional vibration mode, which is captured both by the strain gage and PZT signals. 


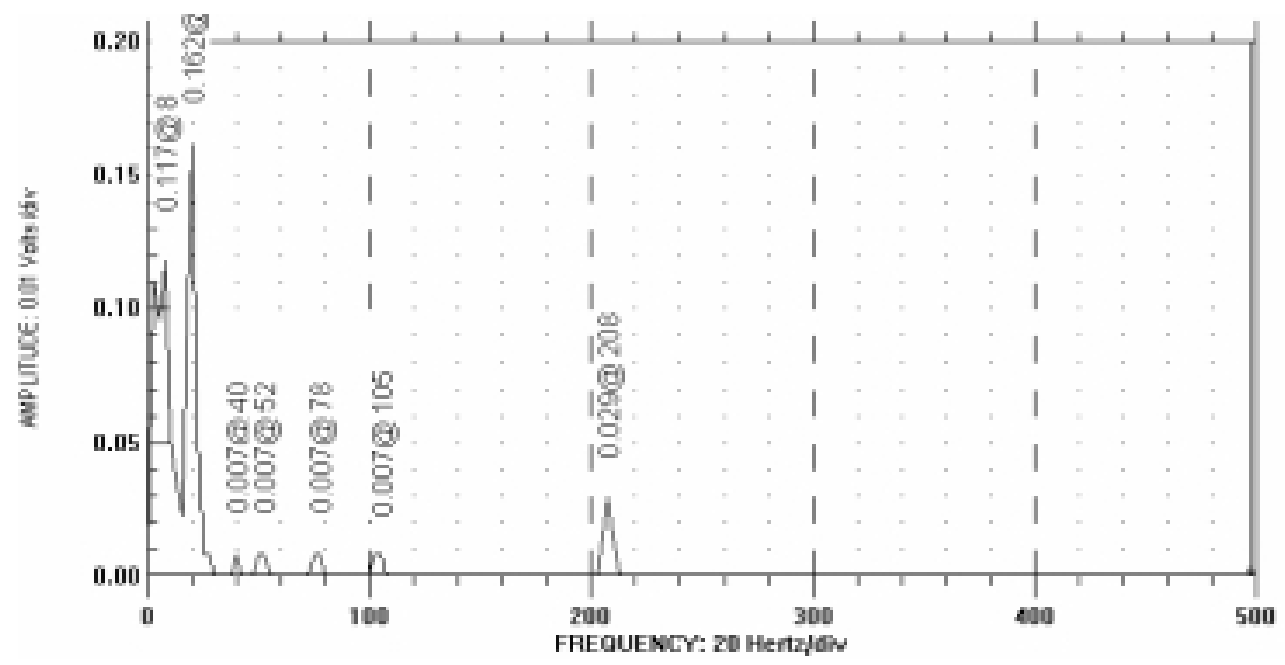

(a)

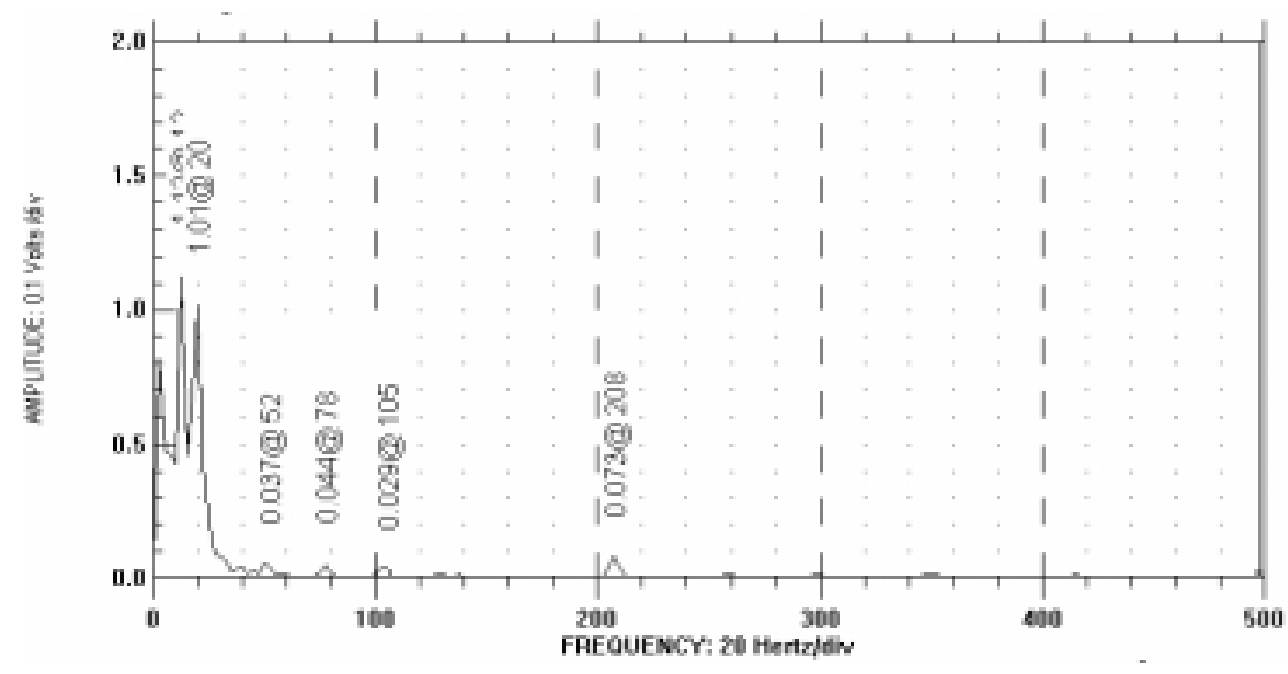

(b)

Fig. 31. Frequency spectrums of the steady-state vibrations of the system rotating at speed of $20 \mathrm{~Hz}$ : (a) Strain gages, (b) PZT material.

4. Finally, the free vibration test indicates that the PZT material embedded at the root of the blade has captured all frequency components produced by the strain gages and more.

\subsubsection{Steady-state vibrations}

To simulate the steady state operating conditions, the bladed-rotor system was operated by the variable speed AC motor with speeds of 20 and $40 \mathrm{~Hz}$. The vibration signals were collected from the four sensors whose locations were kept the same for comparison and verification purposes. The frequency span was limited to $500 \mathrm{~Hz}$ after which no observable frequency components were found. Moreover, the frequency resolution was set at $2.5 \mathrm{~Hz}$ imposed by the data acquisition system.

The frequency spectrums for the $20 \mathrm{~Hz}$ running speed are provided in Figs. 31(a) and (b). The strain gage spectrum, Fig. 31(a), shows frequency components at 2, 8, 20, 40, 52, 78, 105 and $208 \mathrm{~Hz}$. The low frequency components $(2 \mathrm{~Hz}$ and $8 \mathrm{~Hz}$ ) represent the rigid body and shaft torsional vibration modes. The highest amplitude 


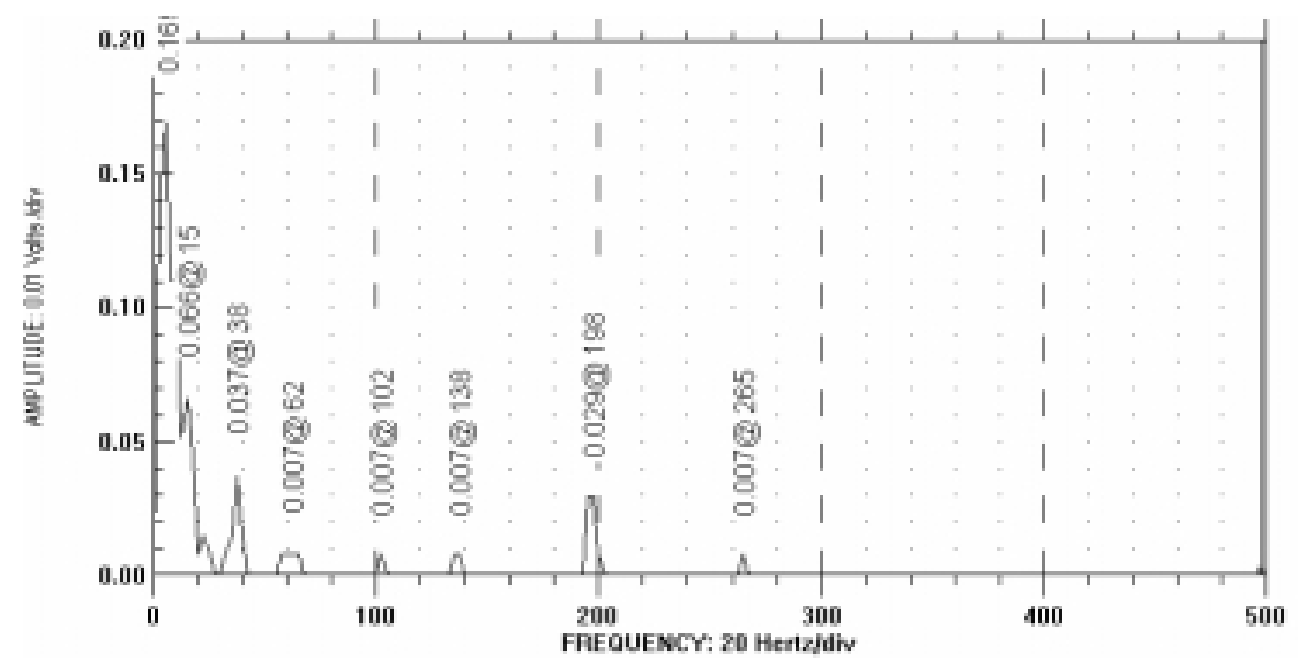

(a)

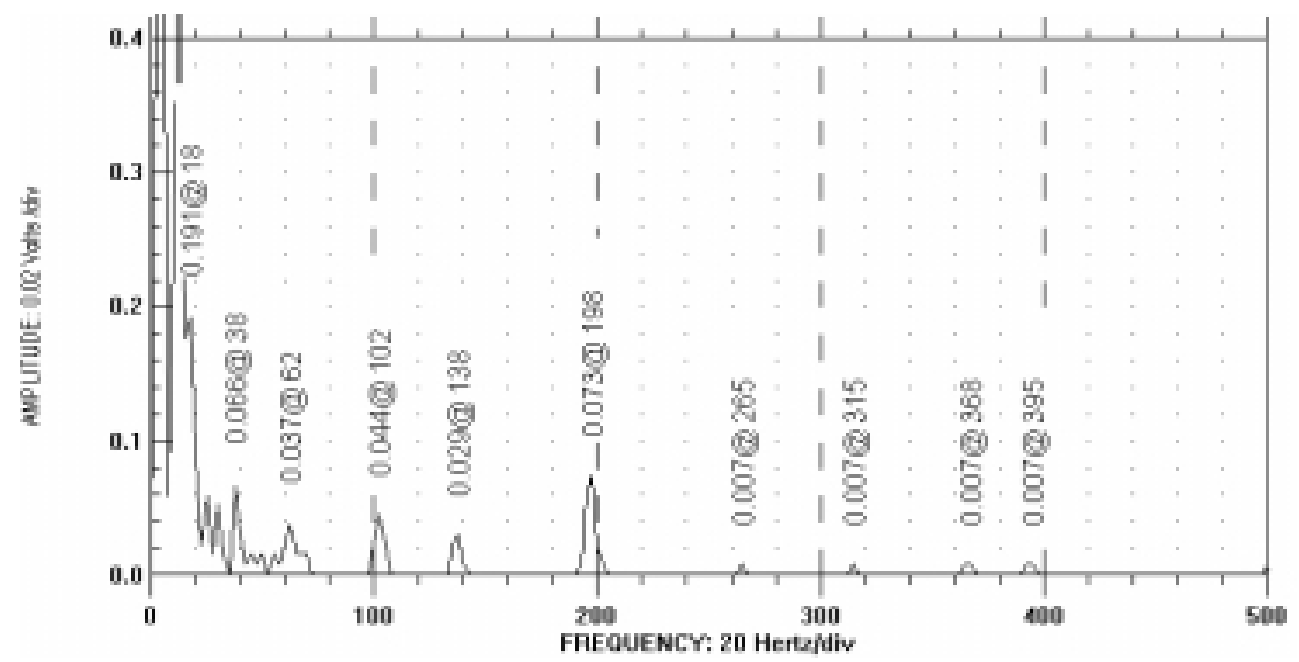

(b)

Fig. 32. Frequency spectrums of the steady-state vibrations of the system rotating at speed of $40 \mathrm{~Hz}$ : (a) Strain gages, (b) PZT material.

is shown for the $1 \mathrm{X}(20 \mathrm{~Hz})$ frequency component related to the imbalance. The $2 \mathrm{X}(40 \mathrm{~Hz})$ component can be linked to the natural frequency of the shaft lateral mode. The $52 \mathrm{~Hz}$ is the blade first bending mode. The $78 \mathrm{~Hz}$ and $105 \mathrm{~Hz}$ excitations are vibration characteristics of the blades since they appeared neither in the proximity probe nor in the accelerometer spectrums. They can be referred as the blade response due to its base excitation at $1 \mathrm{X}$ and $2 \mathrm{X}$ frequencies. The $78 \mathrm{~Hz}$ can be considered as twice the $2 \mathrm{X}$ and the $105 \mathrm{~Hz}$ as 2.5 the $2 \mathrm{X}$ frequencies. This type of response is expected when blades (beams) are excited at the base, as reported by Al-Nassar and Al-Bedoor [22]. The $208 \mathrm{~Hz}$ frequency component, which is captured by the strain gage and PZT spectrums, shows change in the frequency when the system is rotating.

The frequency spectrums of the $40 \mathrm{~Hz}$ running speed are shown in Figs. 32(a) and (b). Although the speed was set at $40 \mathrm{~Hz}$ in the motor controller, the actual rotating speed was measured as $38 \mathrm{~Hz}$ by the keyphasor. Thus the $1 \mathrm{X}$ will appear at $38 \mathrm{~Hz}$ in the spectrums. The strain gage spectrum, Fig. 32(a), indicates low frequencies at $2 \mathrm{~Hz}$, 


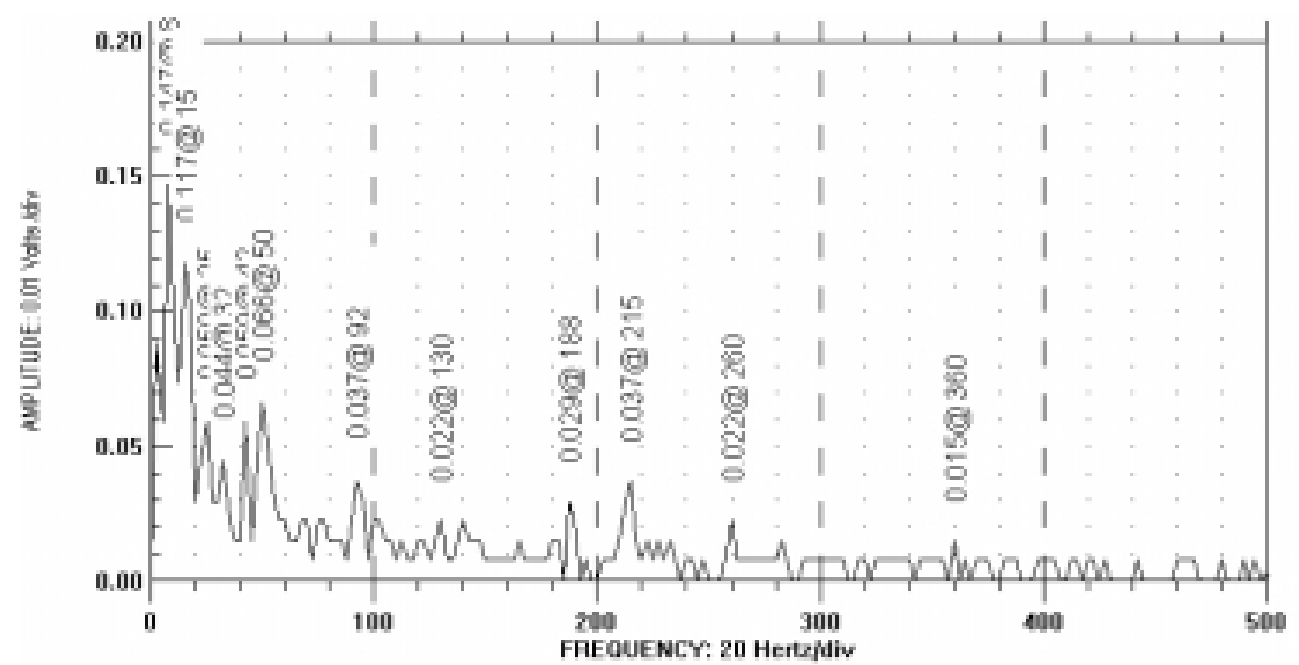

(a)

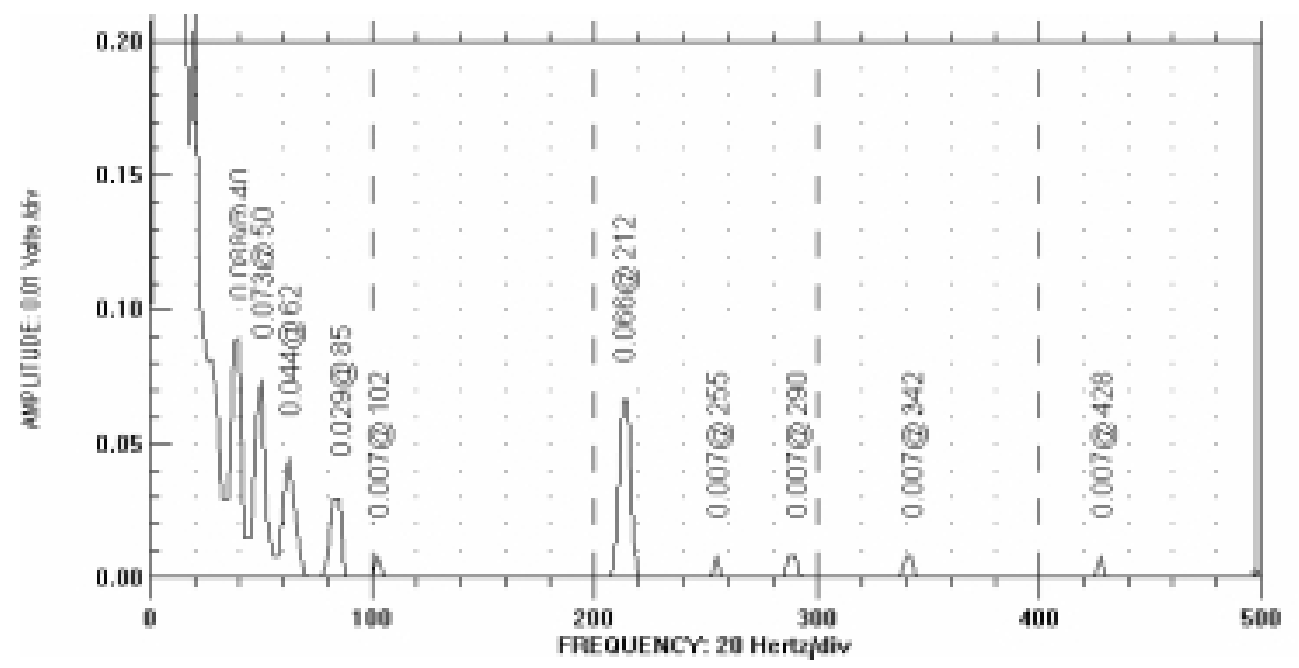

(b)

Fig. 33. Frequency spectrums of the steady-state vibrations of the system rotating at speed of $10 \mathrm{~Hz}$ with blade-to-stator rubbing: (a) Strain gages, (b) PZT material.

$5 \mathrm{~Hz}$ and $18 \mathrm{~Hz}$, with the highest amplitudes. The $1 \mathrm{X}$ frequency is seen in the spectrum together with the blade first bending natural frequency of $62 \mathrm{~Hz}$, which is increased due to the stiffening effect. Also seen are the frequencies at $102 \mathrm{~Hz}$ and $138 \mathrm{~Hz}, 198 \mathrm{~Hz}$ and $265 \mathrm{~Hz}$. The $198 \mathrm{~Hz}$ frequency is in the range of $200 \mathrm{~Hz}$ that was previously observed with the trend of getting lowered when the rotation speed is increased. All the frequency components appearing in the strain gage spectrum are captured by the PZT spectrum of Fig. 32(b). In addition, the PZT spectrum shows frequency components at $315 \mathrm{~Hz}, 368 \mathrm{~Hz}$ and $395 \mathrm{~Hz}$ related to the blade-disk system natural frequencies or to excitations of nonlinear nature.

To this end a number if points are highlighted as follows:

1. The objectives are to examine the signals of the PZT material as compared to those of the strain gages.

2. The blade vibrations at steady state running speeds are characterized by low frequency vibration due to rigid body rotation and shaft torsional vibration, vibration at rotor lateral vibration frequencies like the unbalance 
(1X), vibrations at blade natural frequencies and other frequencies related to shaft bearing system natural frequencies and dynamic interactions between different system components.

3. The PZT shows excellent sensitivity to blade vibrations in the steady-state vibration experiments at all speeds.

\subsubsection{Steady-state vibrations with blade-to-stator rubbing}

In the previous sections, the free and steady-state vibration measurements of blades were presented via two different sensors. Excitation condition that is practically possible occurs when the blades rub the machine housing which is stationary and usually referred to as the stator. In this section blades and shaft vibration signals are monitored when the blades are rubbing one point on the circumference at the rotating speed of $10 \mathrm{~Hz}$. The limitation on the speed was imposed by the danger that was expected when rubbing impact- contact was conducted as too much noise and high vibrations were produced. The rubbing or impact-contact condition is known to produce high impulsive forces in the lateral and axial directions on the blades and is expected to excite many combinations of vibration modes and may result in nonlinear interactions between the system vibration modes.

The vibration frequency spectrums of the blade vibration signals when the rotor is running at $10 \mathrm{~Hz}$ rotating speed with the rubbing condition are shown in Figs. 33(a) and (b). The strain gage spectrum, Fig. 33(a), shows low frequency components at $2 \mathrm{~Hz}, 8 \mathrm{~Hz}, 15 \mathrm{~Hz}, 18 \mathrm{~Hz}, 32 \mathrm{~Hz}, 40$ and $50 \mathrm{~Hz}$ with a broad band frequency base. It was observed that most of these frequencies appeared due to rubbing. Moreover, it was noticed that the amplitude of the blade natural frequency of $50 \mathrm{~Hz}$ was 10 times the amplitude for the no rubbing experiment. In the frequency region higher than $50 \mathrm{~Hz}$, the strain gage spectrum indicates all frequencies (broad band with flat response) and peaks at $92 \mathrm{~Hz}, 130 \mathrm{~Hz}, 188 \mathrm{~Hz}, 215 \mathrm{~Hz}, 260 \mathrm{~Hz}$ and $360 \mathrm{~Hz}$. The equivalent spectrum with no rubbing condition did not yield the broad band and showed only the $225 \mathrm{~Hz}$ and $250 \mathrm{~Hz}$ components. In the PZT material frequency spectrum of Fig. 33(b), the low frequency region is shown to have a broad band with peaks at $10 \mathrm{~Hz}, 40 \mathrm{~Hz}, 50 \mathrm{~Hz}$ and $62 \mathrm{~Hz}$. In addition, the PZT spectrum yields frequency components at $85 \mathrm{~Hz}, 102 \mathrm{~Hz}, 212 \mathrm{~Hz}, 255 \mathrm{~Hz}, 290 \mathrm{~Hz}, 342 \mathrm{~Hz}$ and $428 \mathrm{~Hz}$. These frequencies can be referred to the natural frequencies of the foundation-shaft-blade system that are excited when the blades impact the stator. When the PZT was compared to its equivalence without rubbing two main points were observed: (1) the spectrum without rubbing did not show the broad band in the low frequency region and its distinct frequencies as in the case with rubbing, and (2) the high frequency region had less number of frequency components in the no rubbing experiment. It is also worth mentioning that the flat broad band response of the strain gage spectrum is not shown by the PZT material signal.

Based on studying the frequency spectrums for the rubbing experiments and comparing them to their equivalences with the no rubbing conditions, a number of points can be made as follows:

1. The rubbing condition induces a broad band frequency response in the low frequency region and more vibration amplitudes at the blade natural frequencies. Furthermore, the rubbing condition excites many higher frequency vibrations.

2. The broad band and flat frequency responses in the strain gage spectrums indicate the existence of some problems in the strain gage bonding when the blade tip is impacted by the stator. The spectrums of the PZT material are more realistic and representative than those of the strain gages.

3. The low frequencies indicate excitation of the shaft-rotor torsional vibrations.

4. The rubbing induces axial and lateral impulsive loads on the blades and excites the lateral and torsional vibrations of the shaft.

5. The PZT material produces excellent responses and hence its use can be extended to measure the rotor torsional vibrations.

\section{Comparisons and remarks}

After discussing the experimental results of the free and steady-state vibrations of the bladed-disk-shaft system with the embedded PZT material at the root of one blade and having in mind the results of the finite element analysis presented before, some comparisons between the results is needed, whenever possible. In addition, this step will help in extracting some concluding remarks as follows: 


\subsection{Free and transient vibration results}

Based on the results of the finite element modal and transient analyses presented in Part 1 and those of the experimental free vibrations in Part 2, the following points can be extracted:

1. The $2 \mathrm{~Hz}$ free vibration component appeared in the experiment and did not appear in the finite element modal and transient analysis. Instead the $28 \mathrm{~Hz}$ vibration frequency appeared as the rotational mode in the finite element analysis. The big difference in the frequency can be referred to the short length of the shaft in the finite element model and no consideration of the motor mass moment of inertia.

2. The $38 \mathrm{~Hz}$ frequency appearing in the free vibration experiment and representing the shaft lateral vibration mode did not appear in the finite element modal analysis. Again this is due to the shorter shaft segment taken in the finite element model.

3. The $50 \mathrm{~Hz}$ frequency appearing in the free vibration experiment corresponds to the $52 \mathrm{~Hz}$ frequency in the finite element modal and transient analyses. This is the most important frequency and is shown to be captured by the finite element model as reflected by its corresponding mode and mode shape. The excellent agreement in the blade first bending natural frequency between the finite element model and the experiment indicates excellent capabilities of the PZT material in capturing the blade free vibration mode. This phenomenon is also supported by the strain gage results.

4. The $225 \mathrm{~Hz}$ frequency appeared in the free vibration experiments, but did not appear in the finite element modal and transient analysis as the model did not account for the shaft-bearing system.

5. The $250 \mathrm{~Hz}$ component appeared in the free vibration experiments can be taken equivalent to the $259 \mathrm{~Hz}$ in the finite element modal analysis. This frequency can be thought as a coupled mode between the disk and blades.

6. The $325 \mathrm{~Hz}$ frequency component in the free vibration experiment is shown in the frequency range of 323$343 \mathrm{~Hz}$ in the finite element modal analysis. This is a very important frequency component which is the second blade bending mode. This agreement indicates that the PZT material is excellent in capturing the higher bending modes of the blade vibrations.

7. The PZT in the free vibration experiment showed a frequency component at $450 \mathrm{~Hz}$ that may be related to the torsional vibration mode of blades. In the finite element model this mode appeared in the neighbourhood of $533 \mathrm{~Hz}$.

\subsection{Steady-state vibration analysis}

Based on the steady-state vibration experimental and finite element results at the speeds of $20 \mathrm{~Hz}$ and $40 \mathrm{~Hz}$, the following remarks are emerged:

1. The low frequency vibration at $2 \mathrm{~Hz}$ produced by the experiment was not shown by the finite element simulations due to the shorter segment of the shaft used in the model and due to not accounting for the motor mass moment of inertia. This frequency was not shown by either the blade tip or root vibration or by the PZT material voltage signal in the finite element model. Its appearance in the experiment, in the strain gage and PZT outputs, supports the notion that the PZT reflects the blade vibrations.

2. The $1 \mathrm{X}$ response was captured at all speeds by the finite element model simulations and by the experiments.

3. The blade first free bending vibration frequency appeared in the steady-state experiments and in the finite element simulations.

4. The condition of Blade Pass Frequency (BPF) vibration was not possible to be produced in the experiments. The finite element model simulations showed that the BPF excitation is sensed by the PZT material.

5. The results of rubbing simulation in the finite element model gave little indication of rubbing vibration signature.

\section{Conclusion}

This research work was motivated by the need of measuring the rotating blade vibrations using a reliable, lasting and yet accurate method. This need was developed after the recognition that a good percentage of turbomachinery 
failures occur due to the blade vibrations and fatigue. As a result, the objectives of this research study were identified as developing a method of blade vibration measurements using the root embedded PZT material. The approach to achieve the objectives of the study involved the finite element analysis and experimental studies for the non-rotating (stationary) and rotating blades. Finally, based on the finite element and experimental results presented, one can reach a conclusion that the root embedded PZT material is excellent for rotating blade vibration measurements. This study is to prove the concept and many other developments will refine the final sensor.

\section{Acknowledgments}

The authors gratefully acknowledge the support provided by King Abdulaziz City for Science and Technology (KACST) through Project \# AR-19-14.

\section{References}

[1] A.V. Srinivasan, Vibrations of Bladed-Disk Assemblies - A Selected Survey, Journal of Vibration, Acoustics, Stress, and Reliability in Design - Transactions of the ASME 106 (April 1984), 165-168.

[2] O.A. Bachau and C.H. Hong, Finite Element Approach to Rotor Blade Modelling, The Dynamics and Aeroelastic Stability Modelling of Rotor Systems Technical Workshop, Georgia Institute of Technology, December 1985, 60-67.

[3] L. Jianzhong, T. Seng and C. Zhangzhi, Numerical Analysis of the Dynamic Behaviour of Steam-Turbine Blade Group, Finite Element in Analysis and Design 35 (2000), 337-348.

[4] N. Roy and R. Ganguli, Helicopter Rotor Blade Frequency Evolution with Damage Growth and Signal Processing, Journal of Sound and Vibration 283 (20 May 2005), 821-851.

[5] B. Yardimoglu and D.J. Inman, Coupled Bending-Bending-Torsion Vibration of a Rotating Pre-twisted Beam with Aerofoil Cross-section and Flexible Root by Finite Element Method, Shock and Vibration 11 (2004), 637-646.

[6] R.G. Loewy and N. Khader, Structural Dynamics of Rotating Bladed-disk Assemblies Coupled with Flexible Shaft Motions, AIAA Journal 22(9) (September 1984), 1319-1327.

[7] E.F. Crawley, E.H. Ducharme and D.R. Mokadam, Analytical and Experimental Investigation of Coupled Bladed Disk/Shaft Whirl of a Cantilever Turbofan, Journal of Engineering for Gas Turbines and Power - Transactions of the ASME 108 (October 1986), 567-576.

[8] A. Okabe, Y. Otawara and R. Kaneko, An Equivalent Reduced Modeling Method and Its Application to Shaft-blade Coupled Torsional Vibration Analysis of a Turbine Generator Set, Proceedings of the Institute of Mechanical Engineers, Part A, Journal of Power and Energy 205 (1991), 173-181.

[9] B.O. Al-Bedoor, Dynamic Model of Coupled Shaft Torsional and Blade Bending Deformations in Rotors, Computer Methods in Applied Mechanics and Engineering 169 (1999), 177-190.

[10] A.J. Scalzo, J.M. Allen and R.J. Antos, Analysis and Solution of a Non-Synchronous Vibration Problem in the Last Row Turbine Blade of a Large Industrial Turbine, Journal of Engineering for Gas Turbines and Power-Transactions of the ASME 108 (October 1986), $591-598$.

[11] D.M. Tang and E.H. Dowell, Experimental and Theoretical Study for Non-Linear Aeroelastic Behaviour of a Flexible Rotor Blade, AIAA Journal 31(6) (June 1993), 1133-1142.

[12] J.S. Rao and N.S. Vyas, Determination of Blade Stresses under Constant Speed and Transient Conditions with Nonlinear Damping, Journal of Engineering for Gas Turbines and Power - Transactions of the ASME 118 (April 1996), 424-433.

[13] J. Szwedowicz, S.M. Senn and R.S. Abhari, Optimum Strain Gage Application to Bladed Assemblies, Journal of Turbomachinery Transactions of the ASME 124(4) (October 2002), 606-613.

[14] R.A. Cookson and P. Bandyopadhyay, A Fibre-Optic Laser-Doppler Probe for Vibration Analysis of Rotating Machines, Journal of PowerTransactions of the ASME 102 (July 1980), 607-612.

[15] P. Castellini and C. Santolini, Vibration Measurement on Blades of a Naval Propeller Rotating in Water with Tracking Laser Vibrometer, Measurement 24 (1998), 43-54.

[16] W.C. Laws and A. Muszynska, Periodic and Continuous Vibration Monitoring for Preventive/Predictive Maintenance of Rotating Machinery, Journal of Engineering for Gas Turbines and Power - Transactions of the ASME 109 (April 1987), 159-167.

[17] K. Mathioudakis, E. Loukis and K.D. Papailiou, Casing Vibration and Gas-Turbine Operating-Conditions, Journal of Engineering for Gas Turbines and Power - Transactions of the ASME 112(4) (October 1990), 478-485.

[18] B.O. Al-Bedoor, Reduced-Order Non-Linear Dynamic Model of Coupled Shaft-Torsional and Blade-Bending Vibrations in Rotors, Journal of Engineering for Gas Turbines and Power - Transactions of the ASME 123 (2001), 82-88.

[19] M. Sunar and S.S. Rao, Recent Advances in Sensing and Control of Flexible Structures via Piezoelectric Materials Technology, ASME Applied Mechanics Reviews 52 (1999), 1-16.

[20] ANSYS, Release 7.0, ANSYS, Inc., Canonsburg, Pennsylvania, USA, 2000.

[21] B.O. Al-Bedoor, Transient Torsional and Lateral Vibrations of Unbalanced Rotors with Rotor-to-Stator Rubbing, Journal of Sound and Vibration 229(3) (2000), 627-645.

[22] Y. Al-Nassar and B.O. Al-Bedoor, On the Vibration of Rotating Blade on Torsionally Flexible Shaft, Journal of Sound and Vibration 259(5) (2003), 1237-1242. 

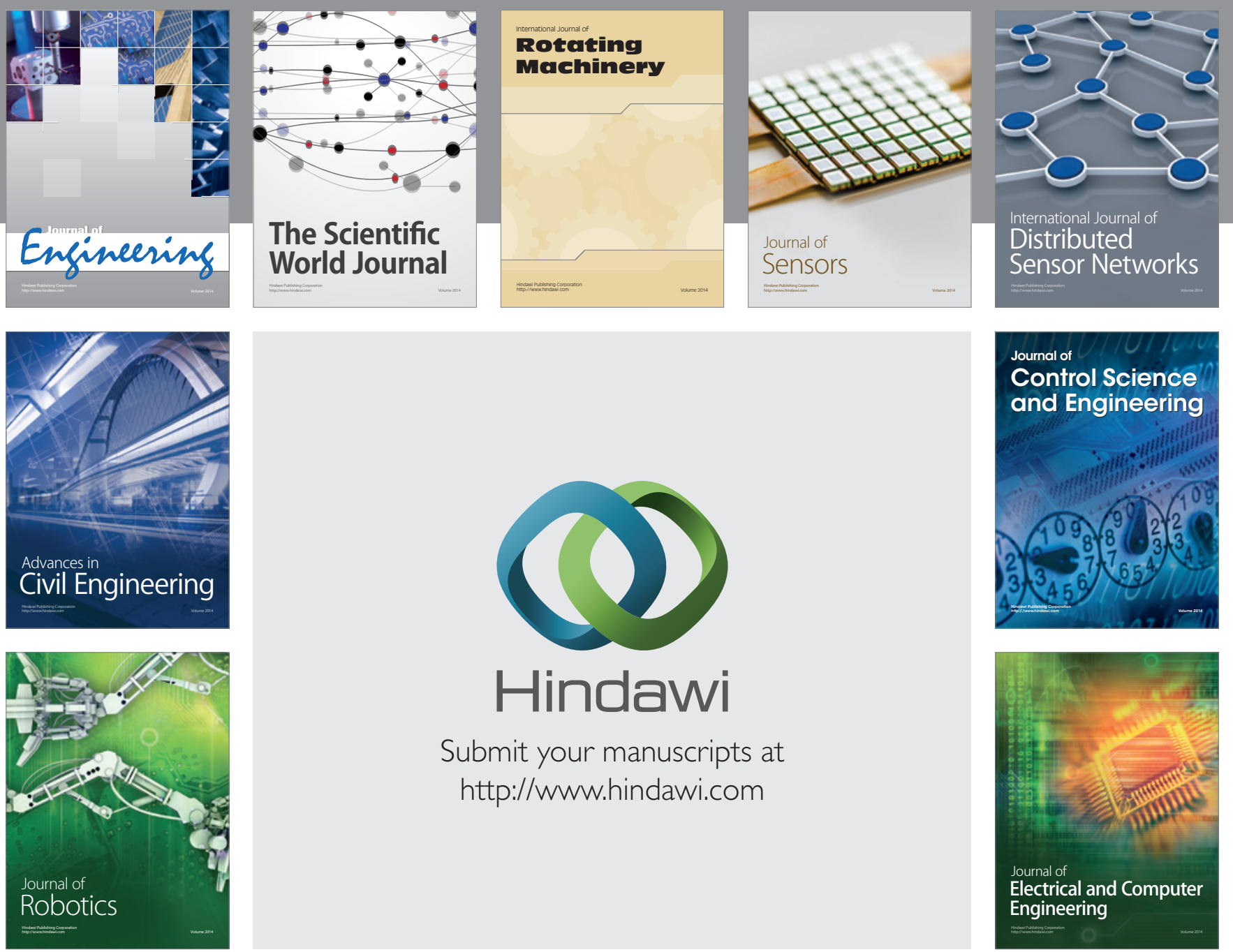

Submit your manuscripts at

http://www.hindawi.com
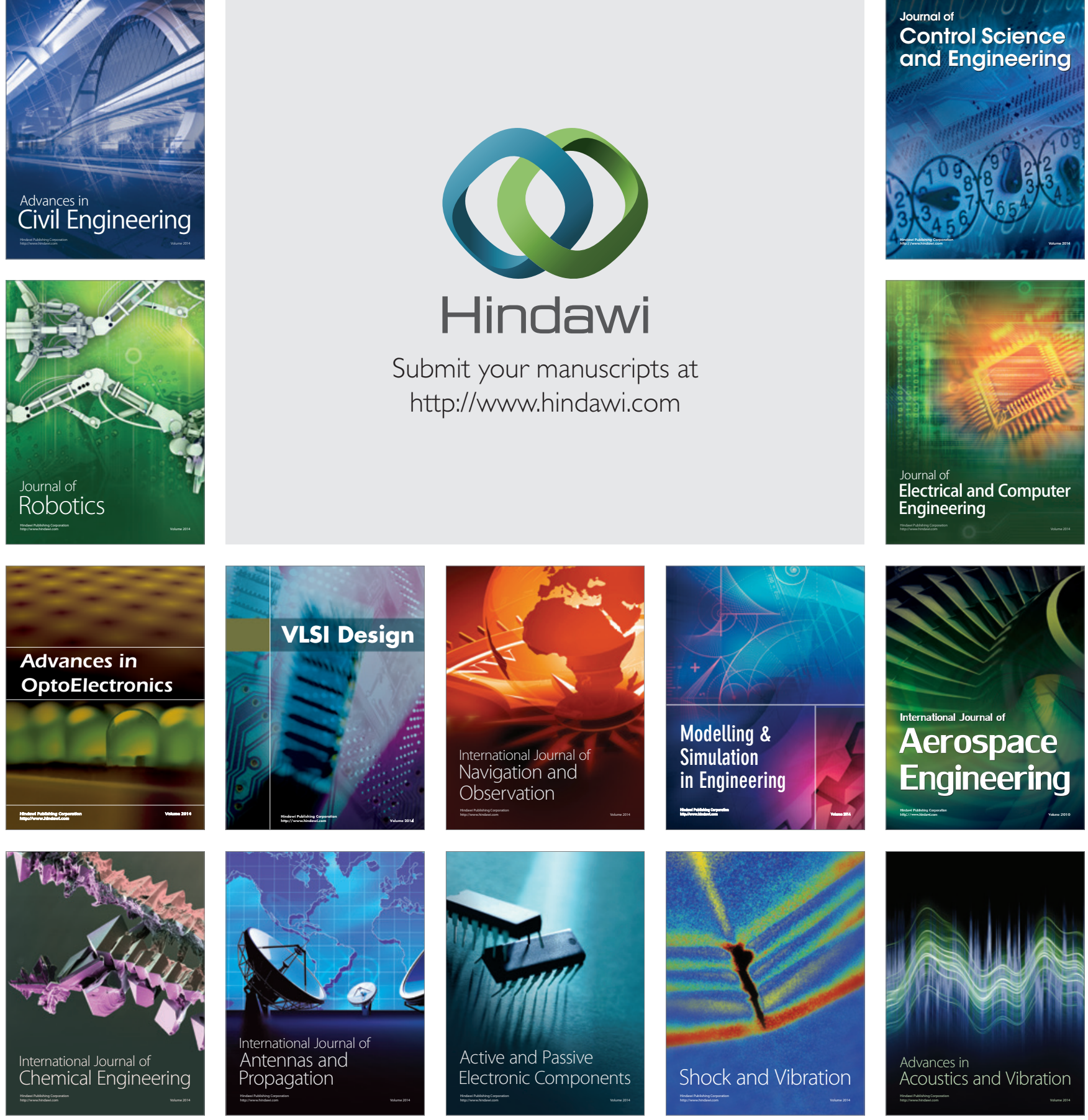